\title{
Application of Optical Triangulation Profilometry and Optical Phase Ranging Profilometry to the Figure Evaluation of Solar Mirrors
}

J. W. Griffin

M. A. Lind

December 1980

Prepared for the Solar Energy Research Institute under Contract XP-9-8366-1 and the U.S. Department of Energy under Contract DE-AC06-76RLO 1830

Pacific Northwest Laboratory Operated for the U.S. Department of Energy by Battelle Memorial Institute 
NOTICE

This report was prepared as an account of work sponsored by the United States Government. Neither the United States nor the Department of Energy, nor any of their employees, nor any of their contractors, subcontractors, or their employees, makes any warranty, express or implied, or assumes any legal liability or responsibility for the accuracy, completeness or usefulness of any information, apparatus, product or process disclosed, or represents that its use would not infringe privately owned rights.

The views, opinions and conclusions contained in this report are those of the contractor and do not necessarily represent those of the United States Government or the United States Department of Energy.

\author{
PACIFIC NORTHWEST LABORATORY \\ operated by \\ BATTELLE \\ for the \\ UNITED STATES DEPARTMENT OF ENERGY \\ Under Contract DE-AC06-76RLO 1830
}

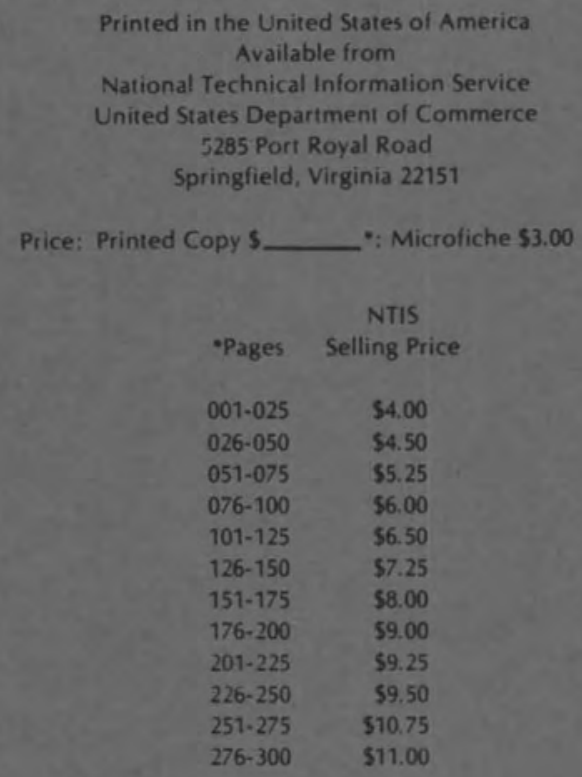




\title{
33679000561342
}

\author{
APPLICATION OF OPTICAL TRIANGULATION \\ PROFILOMETRY AND OPTICAL PHASE RANGING \\ PROFILOMETRY TO THE FIGURE EVALUATION \\ OF SOLAR MIRRORS
}

J. W. Griffin

M. A. Lind

December 1980

Prepared for the Solar Energy Research Institute under Contract XP-9-8366-1 and the U.S. Department of Energy under Contract DE-AC06-76RLO 1830

Pacific Northwest Laboratory Richland, Washington 99352 
.

,

. 


\section{SUMMARY}

The techniques of optical triangulation profilometry (OTP) and optical phase ranging profilometry (OPRP) are proposed for evaluation of the figure of solar mirrors. The theoretical basis for each method is discussed and the results of initial feasibility experiments are reported.

In OTP and OPRP the de-specularized mirror surface is probed with one or more visible laser beams. In OTP, two beams are required for the triangulation of coordinates on the mirror surface. In OPRP the second laser beam is retained within the instrument to form the reference leg of a long wavelength interferometer.

Both methods are particularly adaptable to computer control for fast, automated analysis of mirror surfaces. In addition the proposed devices are compact and sturdy enough for easy implementation in field evaluation programs.

The experimental resolution capability of the unoptimized OTP system is $\geq 0.1$ inch $(2.54 \mathrm{~mm})$. With further improvement of the beam projection and coincidence assessment systems, the design resolution goal of $\geq 0.1 \mathrm{~mm}$ appears achievable. The results of the preliminary resolution capability experiments on the OPRP system are inconclusive. This is thought to be a result of poor performance of components comprising the modulation and detection subsystems. A full assessment of OPRP capability will require a further investigation effort. 
.

.

.

. 


\section{CONTENTS}

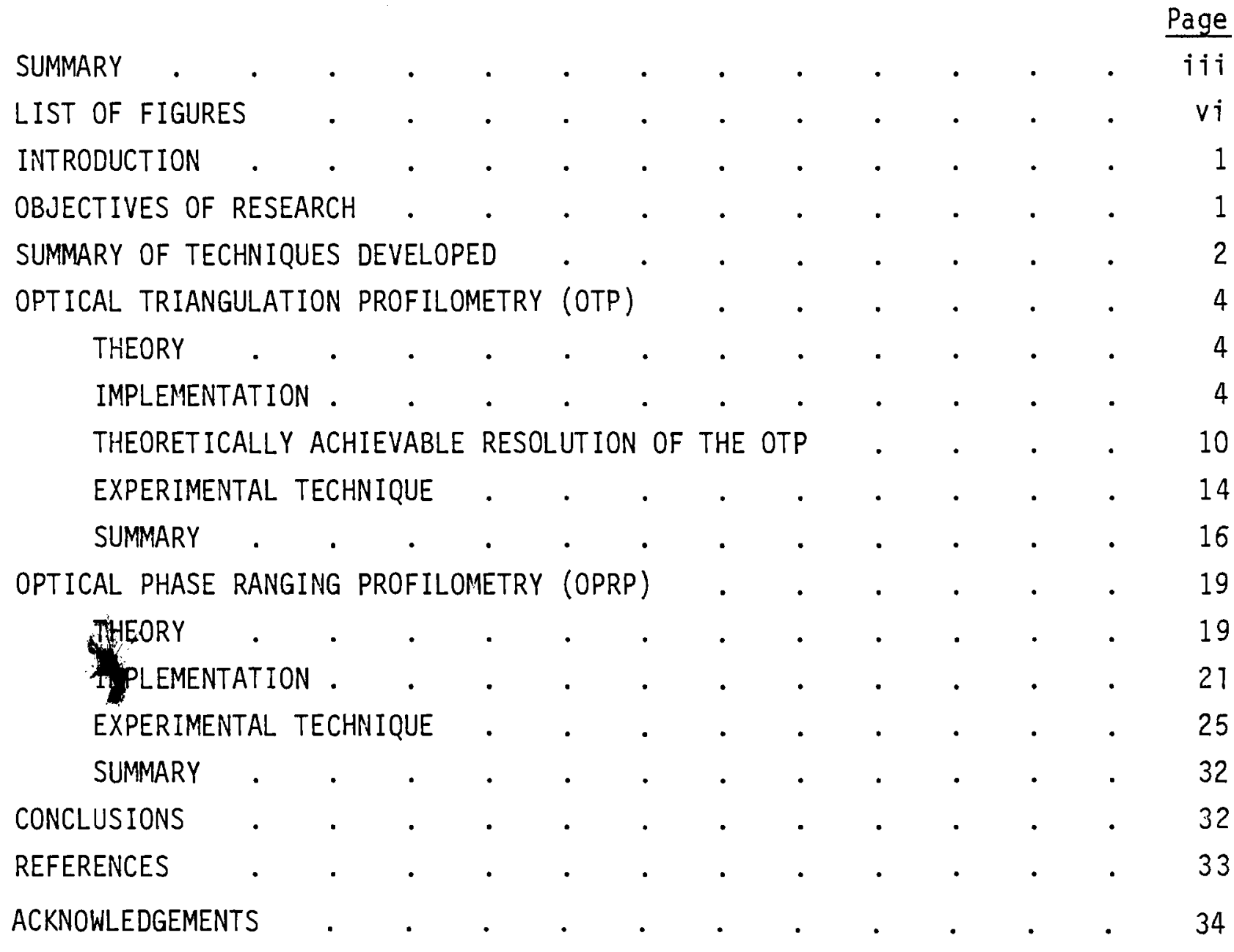


,

,

.

.

. 


\section{LIST OF FIGURES}

Figure

Page

1. Conceptual Drawings of the OTP and OPRP Systems . . . 3

2. Geometry for the Optical Triangulation Profilometer . . 5

3. Schematic of Optical Triangulation Profilometer . . . 6

4. Beam Coincidence Assessment Techniques . . . . . 8

5. Inverse Telescope for Probe and Reference Beams . . . 12

6. Angular Resolution Requirements for Coincidence Discrimination..$\quad \cdot \quad \cdot \quad \cdot \quad \cdot \quad \cdot \quad \cdot \quad \cdot \quad \cdot 13$

7. Scanned Image Signals for Various Target Displacements
from Coincidence . . . . 15

8. Schematic of Field Version of OTP System . . . . $\quad$. 17

9. Photograph of OTP Field System . . . . . . 18

10. Schematic of OPRP System . . . . . . . . . 20

11. Time Dispersion in Re-Imaged Probe Beam Components . . 22

12. Component Configuration for Resolution Evaluation of $50 \mathrm{MHz}$ OPRP System . . . . . . . . . . . 27

13. $500 \mathrm{MHz}$ Modulation System . . . . . . . . $\quad$. 29

14. Photograph of $500 \mathrm{MHz}$ OPRP System . . . . . . 30 
.

,

.

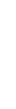

, 


\section{INTRODUCTION}

This report describes the most recent research efforts undertaken by the Pacific Northwest Laboratory during FY80 towards development of fieldapplicable systems for the evaluation of solar mirror figure. One outgrowth of this program has been a survey of techniques for the optical (reflectivity, specularity) and mechanical (figure) evaluation of solar mirrors. The results of this survey are detailed in a report entitled "Evaluation Techniques for Determining the Reflectivity, Specularity, and Figure of Solar Mirrors" (Griffin et al., 1980). Following this report, developmental research was undertaken to apply conventional moiré contouring techniques to the analysis of specular surfaces, i.e., mirrors. This effort was highly successful and is summarized in a report entitled "The Evaluation of Solar Mirror Figure by Moiré Contouring" (Griffin and Lind, 1980). In the current report the techniques of Optical Triangulation Profilometry (OTP) and Optical Phase Ranging Profilometry (OPRP) are theoretically and experimentally outlined and the results of feasibility experiments are discussed.

\section{OBJECTIVES OF RESEARCH}

The objective of the research reported here was to develop prototype instrumentation to quickly and accurately map the surface topography of solar mirrors. The instrumentation was to be capable of evaluating large $\left(4^{\prime} \times 10^{\prime}\right)$ and small ( $\left.1^{\prime} \times 1^{\prime}\right)$ facets of short $\left(<12^{\prime \prime}\right)$ to extremely long $\left(\geq 100^{\prime}\right)$ focal length. It was also desirable that the apparatus possess field service capability; that is, it should allow the evaluation of mirrors mounted on operational heliostats or mounting/tracking frames. The method should be non-contacting, fast enough to evaluate dynamic loading of the module, and possess spatial resolution capability of $\leq 0.1 \mathrm{~mm}$. Both techniques to be proposed satisfy the above requirements. 


\section{SUMMARY OF TECHNIQUES DEVELOPED}

Both the OTP and OPRP methods employ a probe laser beam. In the OTP two laser beams are employed to enable the calculation of surface coordinates by triangulation. In the OPRP concept a single probe beam is utilized in conjunction with a reference beam contained within the instrument. A conceptual drawing of the OTP and OPRP systems appear in Figure 1.

Both OTP and OPRP require that the surface under study possess a nonspecular reflectivity component. This constraint arises from the fact that both systems rely on detection of scattered radiation at the beam-mirror intersection point. The diffuse component of the mirror reflectivity need not be large and is often of sufficient magnitude due simply to dust accumulation on the surface. In the event that it is necessary to augment the diffuse reflectivity, this is easily done by either lightly dusting the mirror surface or by applying a despecularizing plastic overcoat (Griffin and Lind, 1980).

While the above method is entirely valid in the case of front surface mirrors (e.g., plastic film, metal foil, etc.) caution must be taken when extending the method to back surface mirrors of significant thickness. If it is known a priori that the front and rear mirror substrate surfaces possess the same figure then front surface analysis is entirely valid. However, if point by point topography of corresponding coordinates on the front and back surfaces differs then OTP and OPRP are of limited validity and possibly other techniques should be pursued. It has been the observation in this laboratory that in general both front and back surfaces of float glasses possess the same figure (within experimental measurement error) even up to thicknesses of $3 \mathrm{~mm}$. 

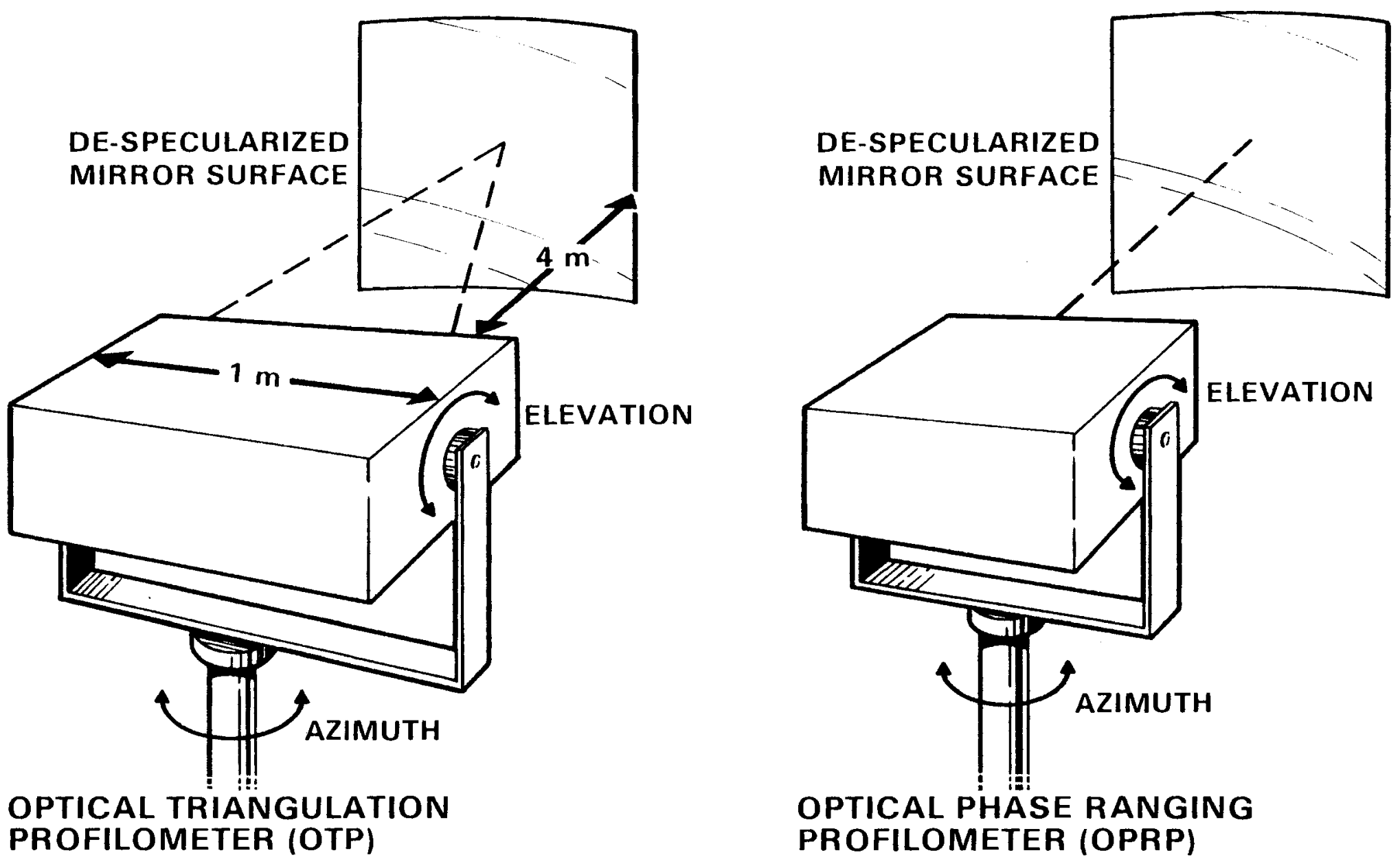

FIGLRE 1. Conceptual Drawings of the OTP and OPRP Systems 


\section{OPTICAL TRIANGULATION PROFILOMETRY (OTP)}

\section{THEORY}

Optical triangulation profilometry is based upon the technique of position location by triangulation. A schematic of the concept appears in Figure 2. Consider two skewed beams, $B_{1}$ and $B_{2}$ (within the same plane) oriented so as to illuminate a common point, $P$, on a surface. If a reference plane is defined which is normal to the plane containing the two beams, the intersection of these two planes forms a line henceforth designated as the reference line. Given the length, $D$, of the reference line and the angles, $\theta_{1}$ and $\theta_{2}$, which the beams make with this line, the perpendicular distance, $L$, from the reference line to the illuminated surface point is given by:

$$
L=D\left(\frac{\tan \theta_{1} \tan \theta_{2}}{\tan \theta_{1}+\tan \theta_{2}}\right)
$$

The relative error in evaluating $L$ is a function of the pointing angle errors, $d \theta_{1}$ and $d \theta_{2}$, and the reference line length error, $d D$, and is given by

$$
\begin{aligned}
\frac{d L}{L}=\frac{d D}{D} & +\left[\frac{1}{\sin \theta_{1} \cos \theta_{1}}-\frac{\sec ^{2} \theta_{1}}{\tan \theta_{1}+\tan \theta_{2}}\right] d \theta_{1} \\
+ & {\left[\frac{1}{\sin \theta_{2} \cos \theta_{2}}-\frac{\sec ^{2} \theta_{2}}{\tan \theta_{1}+\tan \theta_{2}}\right] d \theta_{2} }
\end{aligned}
$$

Note that the relative error in $L$ is dependent not only on $\mathrm{d} \theta_{1}, \mathrm{~d} \theta_{2}$, and $\mathrm{dD}$, but also on the pointing angles $\theta_{1}$ and $\theta_{2}$. This implies that for a given pointing angle uncertainty the relative error in $L$ (i.e., $d L / L$ ) will vary across the test surface.

\section{IMPLEMENTATION}

There are numerous ways to implement such a two-variable (i.e., $\theta_{1}$ and $\theta_{2}$, $D$ is assumed constant) system. One such method is illustrated in Figure 3. The triangle legs are formed by the focused beams of two low power HeNe lasers. The focusing system consists of a microscope objective and a 


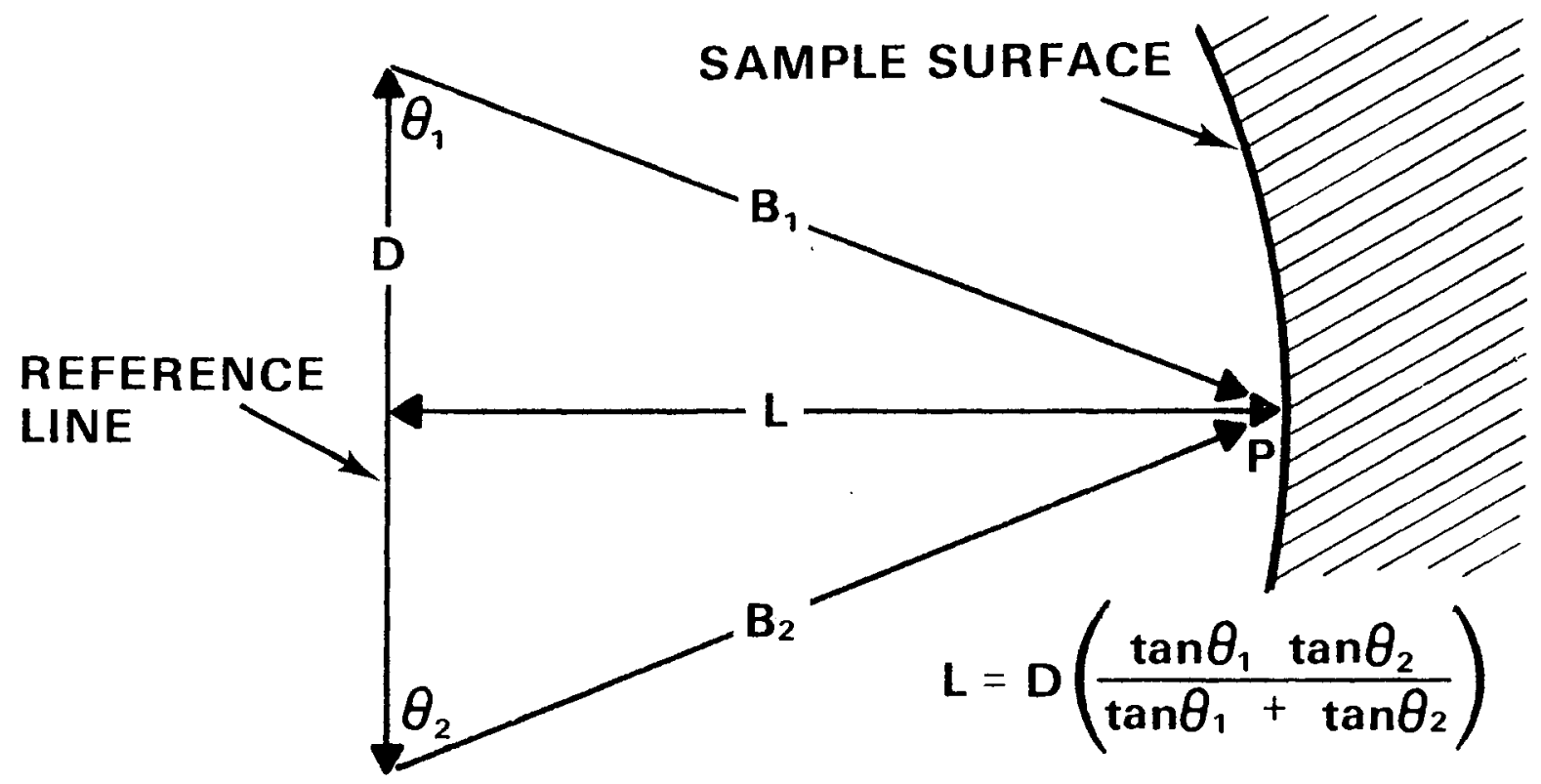

FIGURE 2. Geometry for the Optical Triangulation Profilometer 


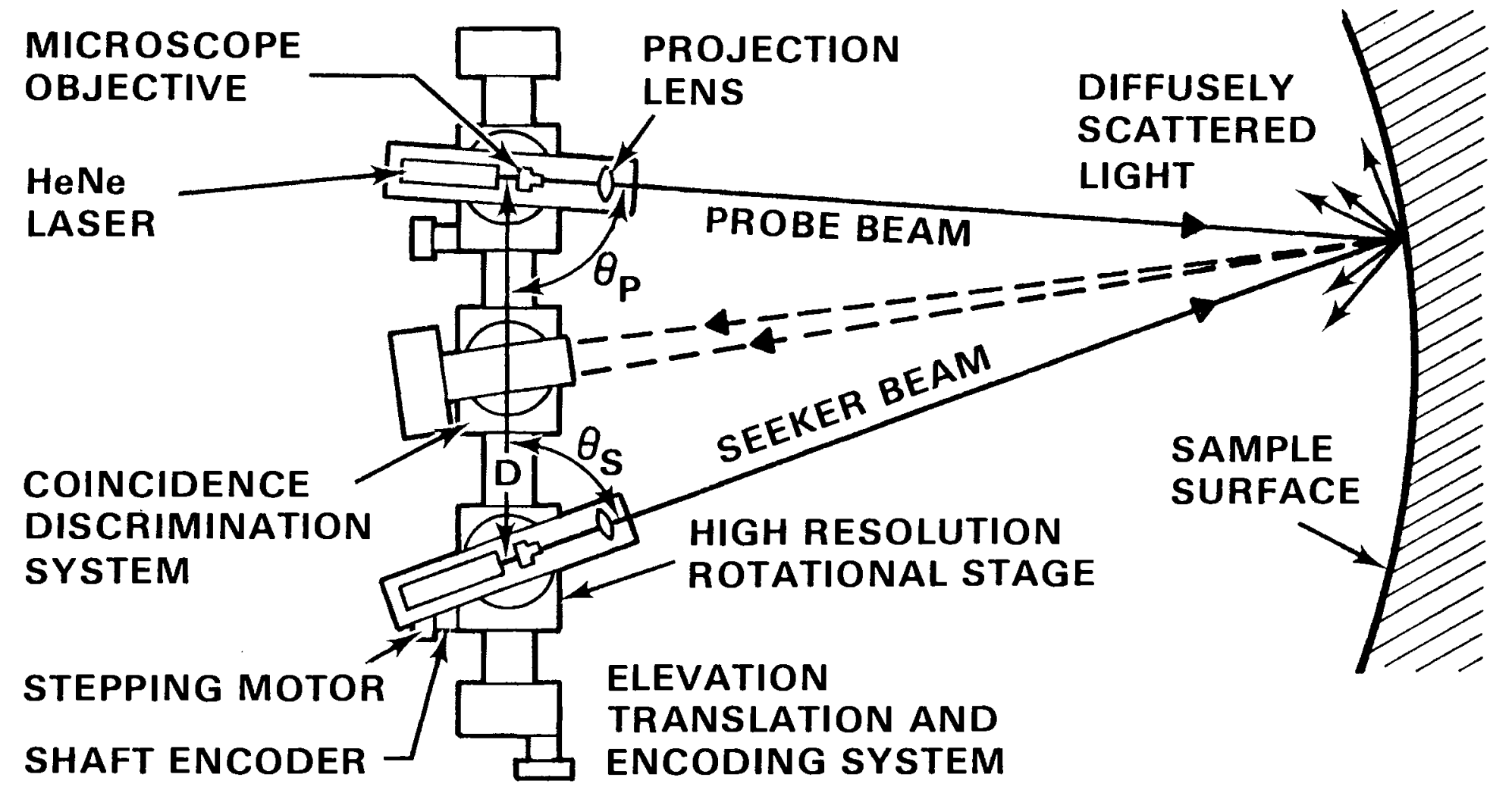

FIGURE 3. Schematic of Optical Triangulation Profilometer 
relatively long focal length lens. The arrangement is essentially that of an inverse telescope. The beams are translated in a high resolution rotary stage driven by stepping motors. Pointing angles are ascertained by installing shaft encoders coaxially with the rotary stage drive shaft and calibrating the encoder-stage system. A key factor in the successful implementation of this method is the technique used for detection of beam coincidence at the test surface.

Two methods of beam coincidence assessment have been implemented in this laboratory. These are illustrated in Figure $4 \mathrm{~A}$ and $4 \mathrm{~B}$. In the scanned image technique the two surface coincident spots are imaged via an auxiliary lens and scanning mirror onto an optical slit. Behind the slit a photomultiplier views the imaged spots. Prior to coincidence the detector output consists of two time resolved pulses with shape determined by the intensity profile of the re-imaged points. As coincidence is approached, the two pulses become less resolved until eventually their images overlap with the result that only one pulse is observed. This ability to resolve the two images (i.e., to detect coincidence) places a basic limitation on the accuracy of the triangulation measurement.

There are three design parameters which will determine the accuracy of the coincidence assessment. First the illuminating laser beams should be focused to the smallest dimensions achievable. In practice this is determined by the laser beam divergence and profile, the focusing optics, and the optical nature of the test surface. In this limiting case the focused spot size will be determined by diffraction at the optical apertures. It is desirable that the test surface be opaque so as to prevent beam spreading due to translucence or second surface reflection. Also the surface normal at the illumination point should be as antiparallel as possible with the beam vector so as not to cause image spreading attributable to oblique illumination. The second parameter with which coincidence accuracy may be controlled is the quality of the auxiliary optics used to reimage the surface incident beams onto the optical slit. The lenses should be of high quality (i.e., design introduced aberrations should be minimized) and of large aperture since the ability to resolve two points with an optical system is chiefly a function of 

BY VIDEO IMAGE ANALYSIS (VIA)

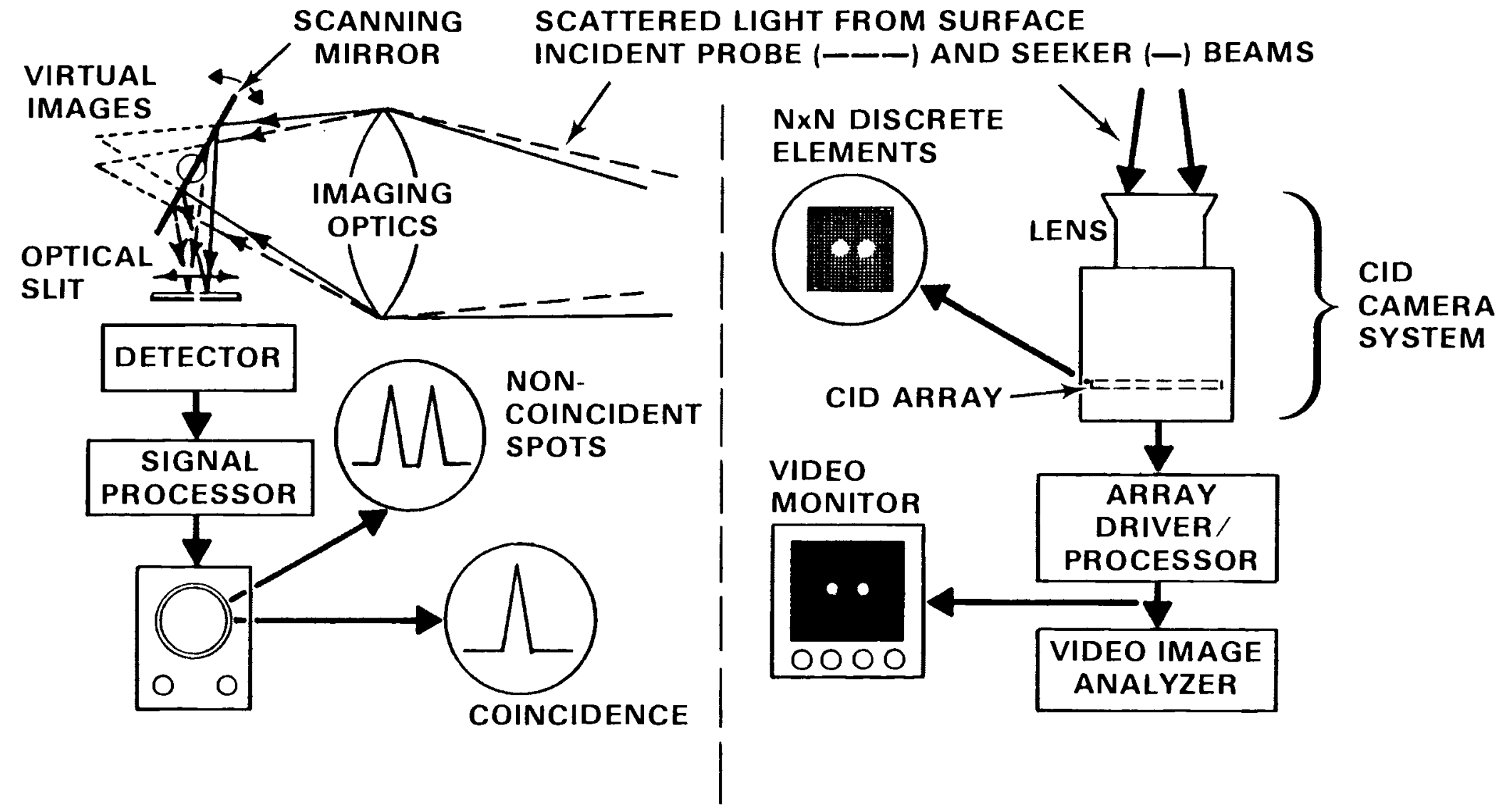

FIGURE 4. Bean Coincidence Assessment Techniques 
aperture. If possible, the optical axis should coincide with the observed points so as to avoid excessive off-axis image aberration (i.e., astigmatism). The third and final determinant of ultimate coincidence resolution is the slit width. The slit width should not exceed the spot image size and in general should be kept as small as possible consistent with a clean signal level.

The second method of beam coincidence assessment investigated in this laboratory is that of video image analysis (VIA). The system is depicted in Figure 4B. In VIA the surface incident beams are re-imaged with high quality optical elements onto a CID (charge injection device) array. The CID array is composed of an N x M (in our case $244 \times 248$ ) matrix of addressable detector elements. Such a system is conducive to mathematical image processing whereby image contrast can be enhanced and the optical resolution capability greatly increased as compared to typical non-processing detection techniques. The camera optics should be chosen to produce the largest reasonable image size on the detector. This allows a high number of image sampling points and increases the credibility of mathematical processing algorithms. Note that such a system requires microprocessor and/or minicomputer interfacing in order to provide fast analysis of image data.

For feasible rapid mirror evaluation by OTP the entire system should be operated under microprocessor and/or minicomputer control. Whereas microprocessor control is certainly satisfactory for mechanical operations and some image analysis, the massive memory storage capability of the minicomputer along with its high speed arithmetic assets greatly enhances OTP capability.

Under microprocessor/minicomputer control a typical measurement algorithm could be summarized as follows. For the sake of clarity the two illumination beams will be designated as probe and seeker. The probe beam selects the surface point to be metered and the seeker beam seeks to establish coincidence at the same point to provide the additional pointing angle necessary for the measurement. Typically surface scans (by the probe beam) would be horizontal (or azimuthal if the elevation is other than zero) across the mirror surface with elevational increments following the retrace at the end of a locus. The measurement algorithm is initiated by scanning the probe 
beam to a selected surface point. The seeker beam is skewed until the coincidence discriminator views two images at which time a seek-feedback operation is initiated thereby driving the two beams to coincidence. An output from the coincidence discriminator triggers data collection (i.e., shaft encoder output of the rotary stages) and storage. The algorithm could then be repeated until the data set was deemed complete. Data could be analyzed on a point by point basis during the course of the collection algorithm or a comprehensive analysis of the data matrix could be deferred until the end of a locus or set of loci. The former is probably a more advisable situation if speed is not a primary factor since it is not highly demanding of computer memory and it allows recognition and re-sampling of spurious data.

\section{THEORET ICALLY ACHIEVABLE RESOLUTION OF THE OTP}

It is appropriate at this point to generate the fundamental relations necessary for estimating the theoretical resolution capability of the OTP and to determine whether the operational constraints and requirements are within the capability of available apparatus.

Consider first the angular resolution requirements of the beam pointing rotary stages. Designating $\theta_{1}$ as $\theta_{p}$ (for "probe" beam) and $\theta_{2}$ as $\theta_{s}$ (for "seeker" beam) we wish to establish the change $d \theta_{s}$ in seeker beam pointing angle as a function of the relative displacement, $\frac{d L}{L}$, of the test surface for constant $D(d D=0)$. The relation is

$$
d \theta_{s}=\frac{d L}{2 L}\left[\frac{1}{\sin \theta_{s} \cos \theta_{s}}-\frac{\sec ^{2} \theta_{s}}{\tan \theta_{p}+\tan \theta_{s}}\right]^{-1}
$$

Choosing $D=1 \mathrm{~m}$ and $L=4 \mathrm{~m}$ the calculated $d \theta_{s}$ for $d L=0.1 \mathrm{~mm}$ at $\theta_{p}=\theta_{s}$ is 0.63 arc seconds. This resolution is within the capability of currently available precision rotational stages. Note that if deemed necessary, this stringent resolution requirement could be relieved by simply decreasing $L$ (i.e., by moving the instrument closer to the test surface). 
The above analysis assumes that the laser beams can be focused to infinitely small points and that perfect coincidence may be established. It is appropriate then at this point to analyze the performance of an optimum focusing system. The Gaussian beam from a laser operating in the TEM transverse mode at wavelength $\lambda$ can be focused to a spot of diameter

$$
b=\frac{4 \lambda}{\pi} \frac{f}{a}
$$

where $f$ is the focal length of the lens and $a$ is the diameter of the collimated incident beam. The beam diameter is defined as twice the radial distance at which the beam irradiance falls to $1 / e^{2}$ of its value at beam center. As an example for $\lambda=6328 \AA$ (HeNe) a microscope objective of $8 \mathrm{~mm}$ focal length will focus a $1 \mathrm{~mm}$ diameter collimated beam to a $6.45 \mu \mathrm{m}$ diameter. While it appears that the focused spot diameter can be decreased indefinitely by simply decreasing the objective focal length, one must avoid overfilling the relatively long focal length projection lens used in the inverse telescope arrangement. The purpose of this lens is to project the focused laser beam onto the test surface. The optical arrangement appears in Figure 5. The magnification of this system is given by

$$
M=\frac{S_{I}-f}{f}
$$

where $f$ is the focal length of the projection lens and $S_{I}$ is the distance from this lens to the test surface. For a lens of $200 \mathrm{~mm}$ focal length and $S_{I}=4 \mathrm{~m}$ the magnification is 19 . This means that the $6.45 \mu \mathrm{m}$ diameter spot formed by the microscope objective is magnified to $123 \mu \mathrm{m}$ on the test surface. Clearly the ability to resolve the non-coincidence condition is dependent upon the size of the illumination spots and this should be a key consideration in the design of the coincidence discriminator.

The heart of the coincidence discriminator is the optical system used to re-image the surface incident spots onto the optical slit or CID array. Consider the basic problem of resolving two point sources with an optical system. According to the Rayleigh criterion two objects are resolved when 


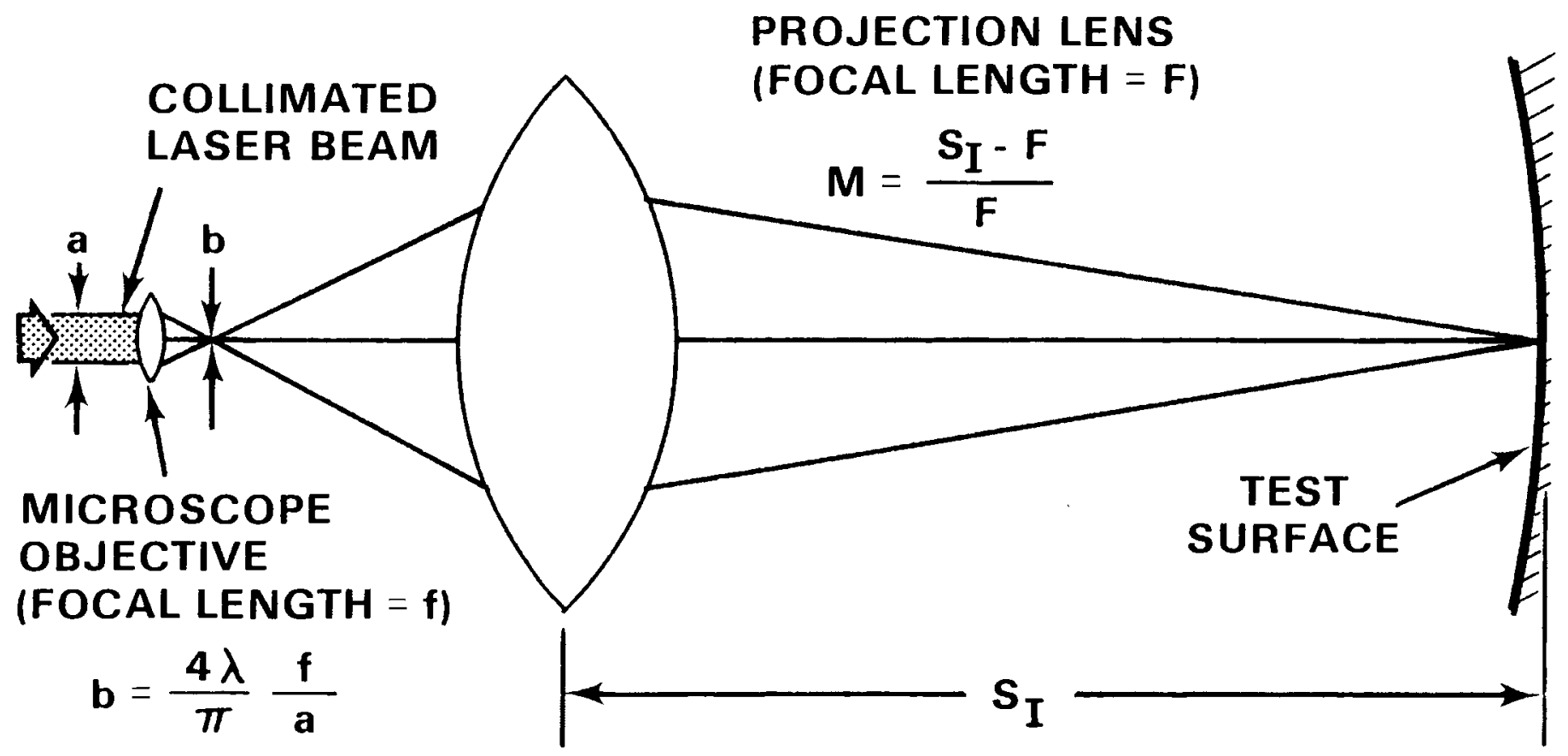

FIGURE 5. Inverse Telescope for Probe and Reference Beams 
the midpoint of the intensity distribution falls to $80 \%$ of either peak. While this definition is rather arbitrary and objects can indeed be resolved at higher midpoint minima it is the basis for the following discussion. For a given wavelength, $\lambda$, and aperture (lens diameter), $d$, two objects must have a minimum angular separation to be resolved. The resolution angle is given by

$$
\phi_{\min } \cong \frac{1.22 \lambda}{d}
$$

This relation can be used to calculate the minimum required lens diameter to be used in the coincidence discriminator. It is first necessary to calculate the angular separation between non-coincident spots (assumed to be points) at the desired spatial resolution. The situation is depicted in Figure 6. If the desired OTP system resolution is $\mathrm{dL}(0.1 \mathrm{~mm}$ in this case) the minimum lens diameter is given by

$$
d \simeq \frac{1.22 \lambda}{\phi \min }=\frac{1.22 \lambda}{(\Delta \mathrm{S} / L)}=\frac{1.22 \lambda}{(\Delta L)(\alpha) / L}
$$

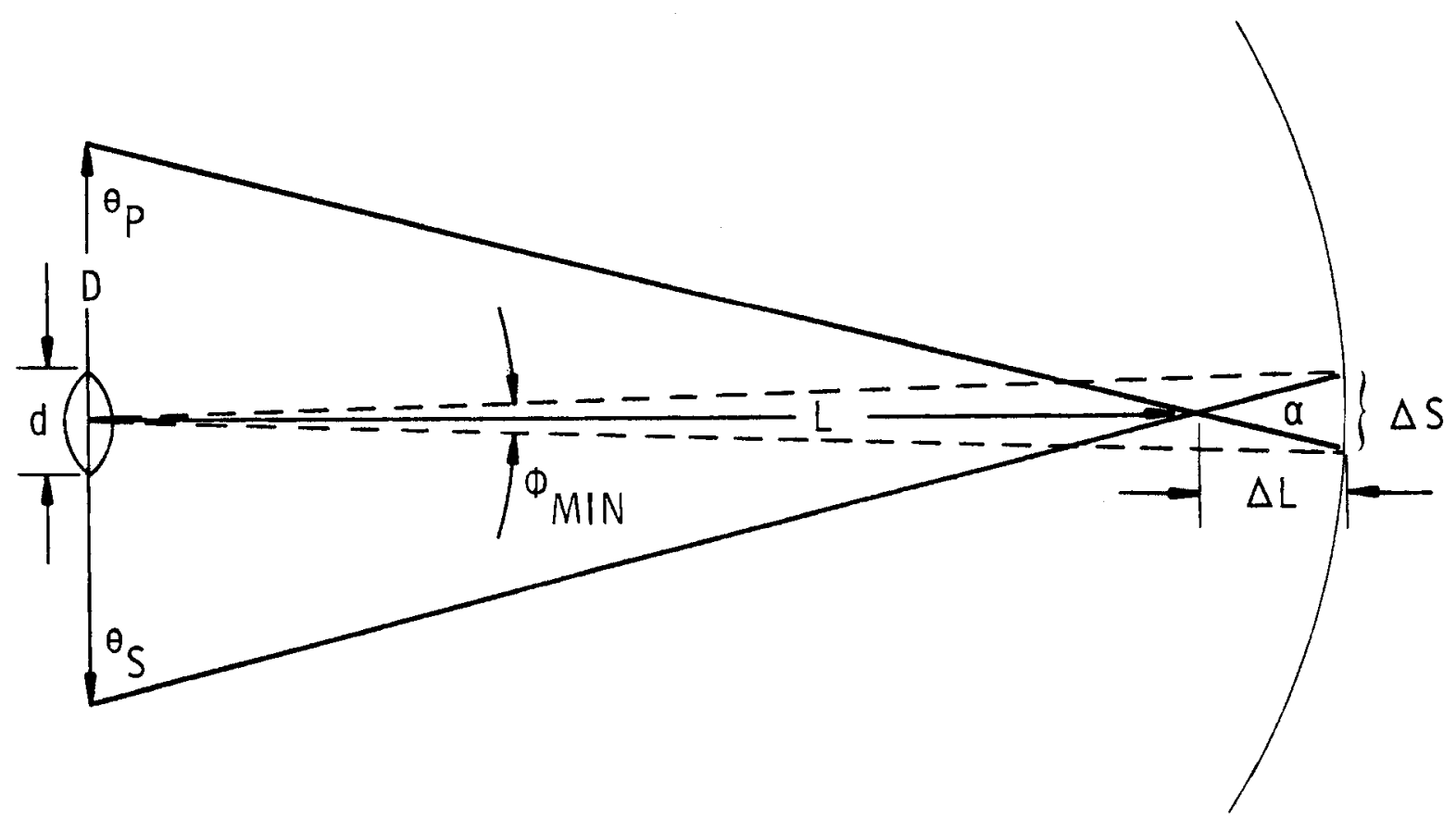

FIGURE 6. Angular Resolution Requirements for Coincidence Discrimination 
Once again taking $\lambda=6328 \AA, D=1 \mathrm{~m}, \mathrm{~L}=4 \mathrm{~m}, \Delta \mathrm{L}=0.1 \mathrm{~mm}$, and $\alpha=0.249$ radians (for $\theta_{p}=\theta_{s}=82.87^{\circ}=1.45 \mathrm{rad}$ ) the minimum allowable lens diameter is $12.4 \mathrm{~cm}$ ( $\sim 5$ inches). This rather large aperture requirement suggests that perhaps reflective optics such as first surface spherical or parabolic mirrors should be substituted for refractive elements when cost is a consideration.

\section{EXPERIMENTAL TECHNIQUE}

A prototype system of design similar to that depicted in Figure 3 was assembled to enable a cursory evaluation of the concept. The probe and seeker beams were generated by two $2 \mathrm{~mW}$ HeNe lasers illuminating the optical axis of an inverse telescope arrangement consisting of a microscope objective and projection lens of $0.8 \mathrm{~mm}$ and $200 \mathrm{~mm}$ focal length respectively. The beams illuminated a translatable target which allowed assessment of the experimental resolution. D was approximately $1 \mathrm{~m}$ and $\mathrm{L}$ approximately $3 \mathrm{~m}$. For coincidence assessment the two previously described techniques were used. For the scanned image technique a $5 \mathrm{~cm}$ diameter, $200 \mathrm{~mm}$ focal length lens imaged the target incident spots onto a scanning mirror (resonant frequency $450 \mathrm{~Hz}$ ). Actually it was necessary to image slightly behind the mirror so that the virtual point images would indeed translate when the mirror was driven. These virtual images were re-imaged with magnification $\sim 2.5$ onto an optical slit. Detection was performed by a high speed photomultiplier tube. The photodetector output and its derivative were observed on an oscilloscope. A series of oscillographs depicting signal appearance at coincidence and for target displacements of $0.1,0.2,0.3,0.4$ and 0.5 inches $\left(\theta_{p} \simeq 90^{\circ}\right)$ appears in Figure 7. Note that loss of coincidence is clearly visible for a target displacement of 0.1 inch $(2.5 \mathrm{~mm})$. It is believed that further mechanical, optical, and electronic optimization would extend the achievable resolution to $0.1 \mathrm{~mm}$.

VIA coincidence assessment was also attempted on a limited basis. The scanned image system was replaced with a CID camera equipped with a $f / 1.8$ zoom lens $(12.5-75 \mathrm{~mm})$. Lens focal length was set at $75 \mathrm{~mm}$ for all observations and the detected spot images were viewed on a video monitor. Coincidence 


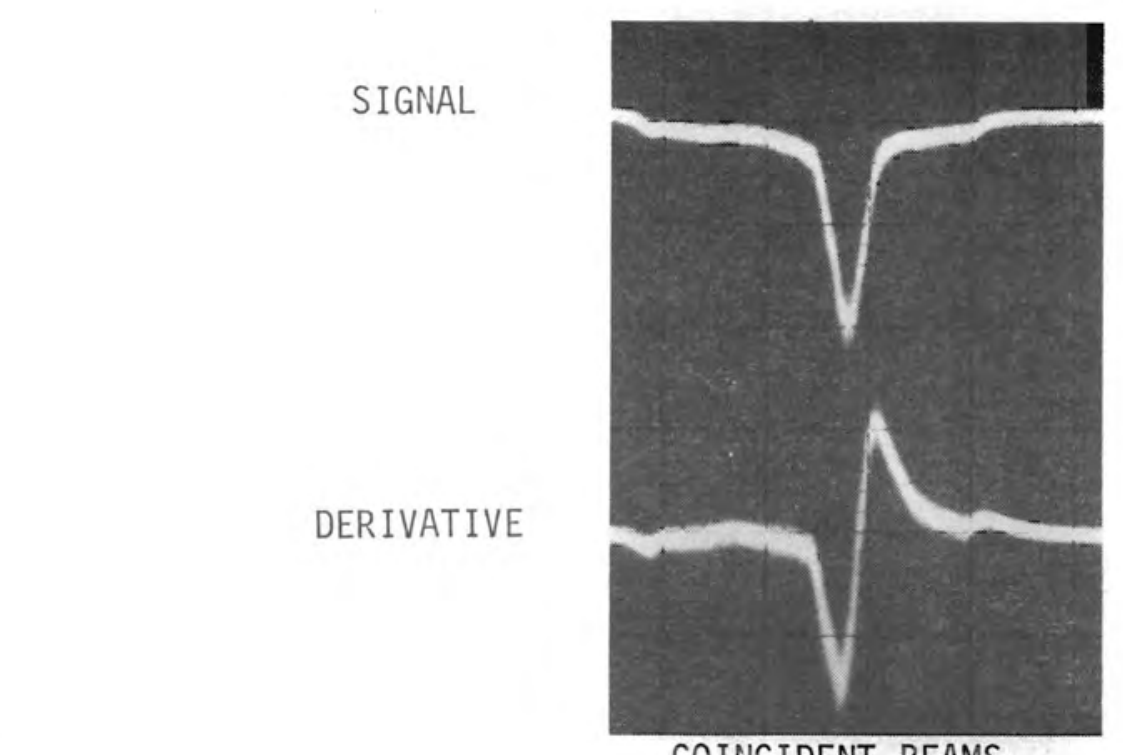

COINCIDENT BEAMS

它

SIGNAL

DERIVATIVE

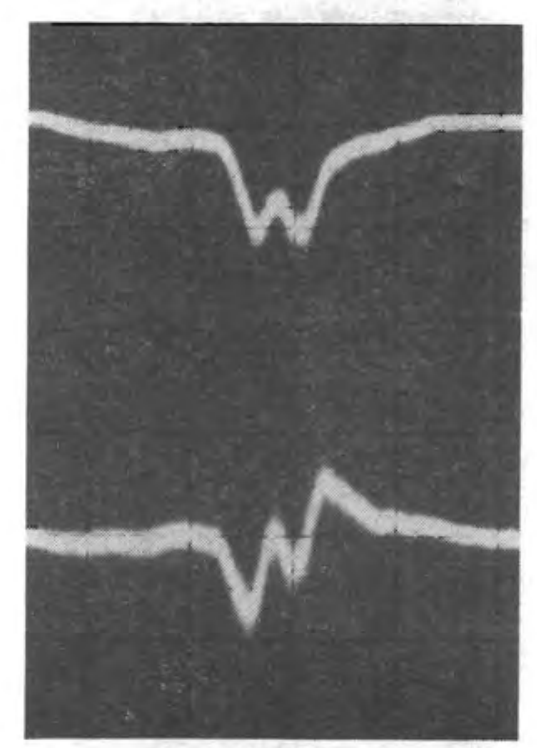

$\Delta=0.3^{\prime \prime}$

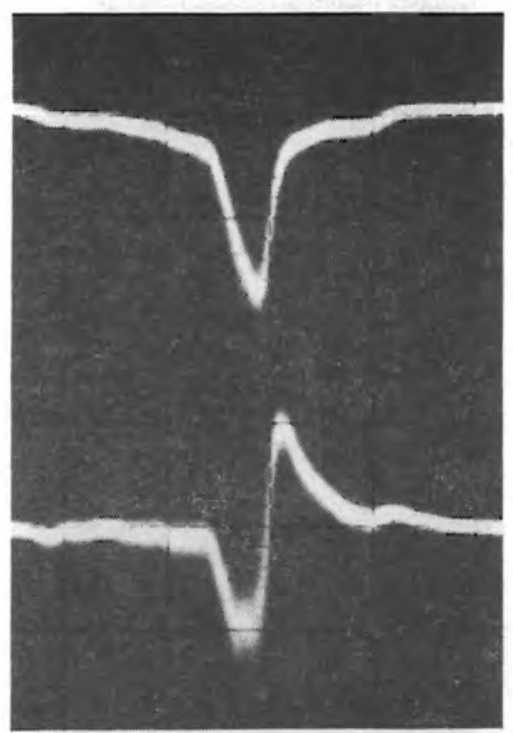

$\Delta=0.1^{\prime \prime}$

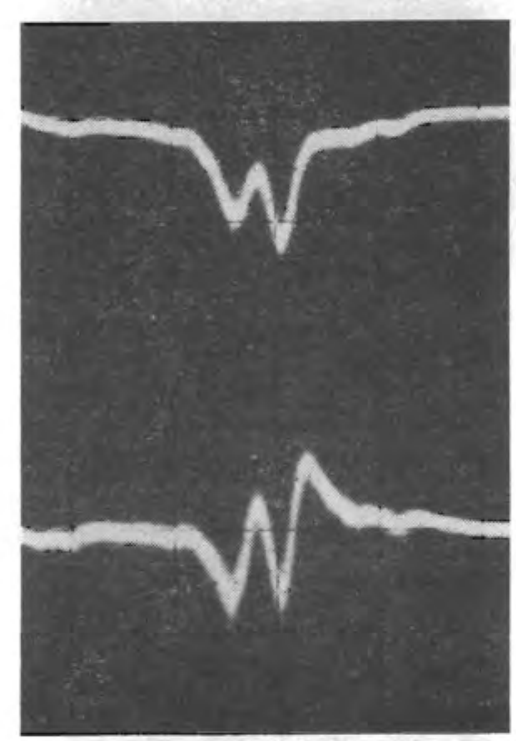

$\Delta=0.4^{\prime \prime}$

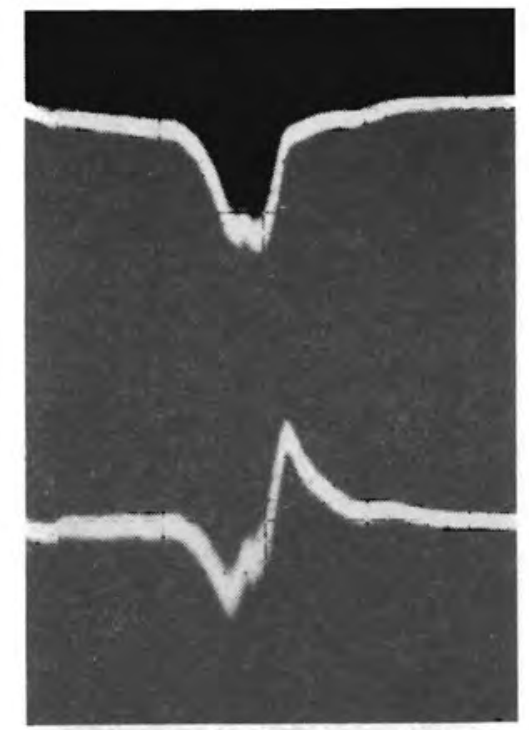

$\Delta=0.2^{\prime \prime}$

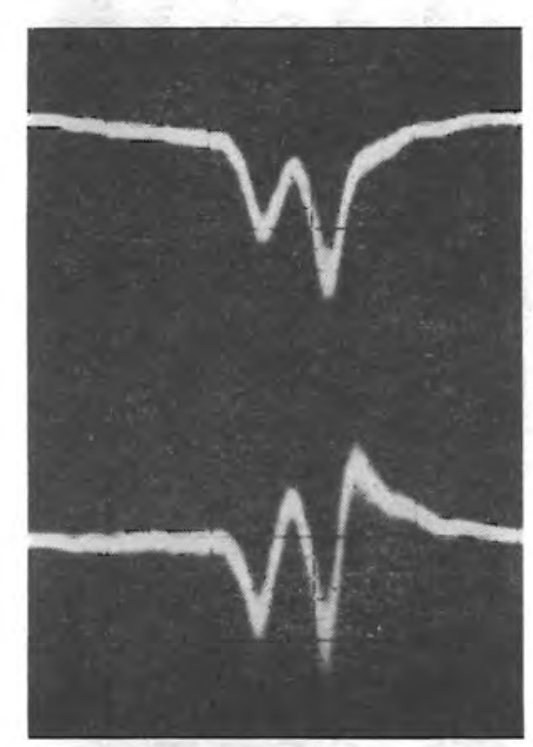

$\Delta=0.05^{\prime \prime}$

FIGURE 7. Scanned Image Signals for Various Target Displacements from Coincidence 
assessment was judged by a human observer. Achievable resolution was deemed comparable to that obtained with the scanned image technique, i.e., $\geq 2.5 \mathrm{~mm}$.

It should be mentioned that the limited dynamic range of the CID array elements generally requires attenuation of the probe and seeker beam intensities. This may be accomplished either by attenuating the beam prior to target incidence (e.g., with neutral density filters), using a test surface de-specularizing overcoat of lower reflectivity, or by stopping down the camera lens.

While the above OTP arrangement is certainly conducive to resolution evaluation it is too cumbersome for field use. With the field capability constraint in mind another prototype version of the OTP was designed. A schematic of this system appears in Figure 8 . A photograph of the actual experimental device appears in Figure 9. In this system both probe and seeker beams are derived from one laser by splitting the laser output via a dual prism arrangement. The split images are then vignetted with circular apertures and directed toward the test surface with front surface mirrors. Note that the probe beam mirror is stationary whereas the seeker beam mirror is positioned by a precision rotary stage $\left(\theta_{s}\right)$. The probe beam is scanned by rotating the support arm at its midpoint with an additional rotary stage $\left(\theta_{A}\right)$. While the functional relationship between $L, D, \theta_{S}$ and $\theta_{A}$ differs from the previous design, the apparatus remains a two variable system. Beam coincidence is once again assessed by a VIA system mounted to view along the probe beam direction. Such a technique provides for automatic scanning of the camera and avoids image aberration attributable to off-axis viewing. The resolution performance of this system is identical to that achieved with the previous design using VIA coincidence discrimination.

\section{SUMMARY}

The OTP systems previously discussed exhibit capability for the figure assessment of large surface areas, e.g., mirrors. Since achievable resolution of the unoptimized prototype systems is at least $2.5 \mathrm{~mm}$, it is reasonable to 
TO TEST SURFACE

\section{I \\ CID CAMERA}

PROBE BEAM SYSTEM

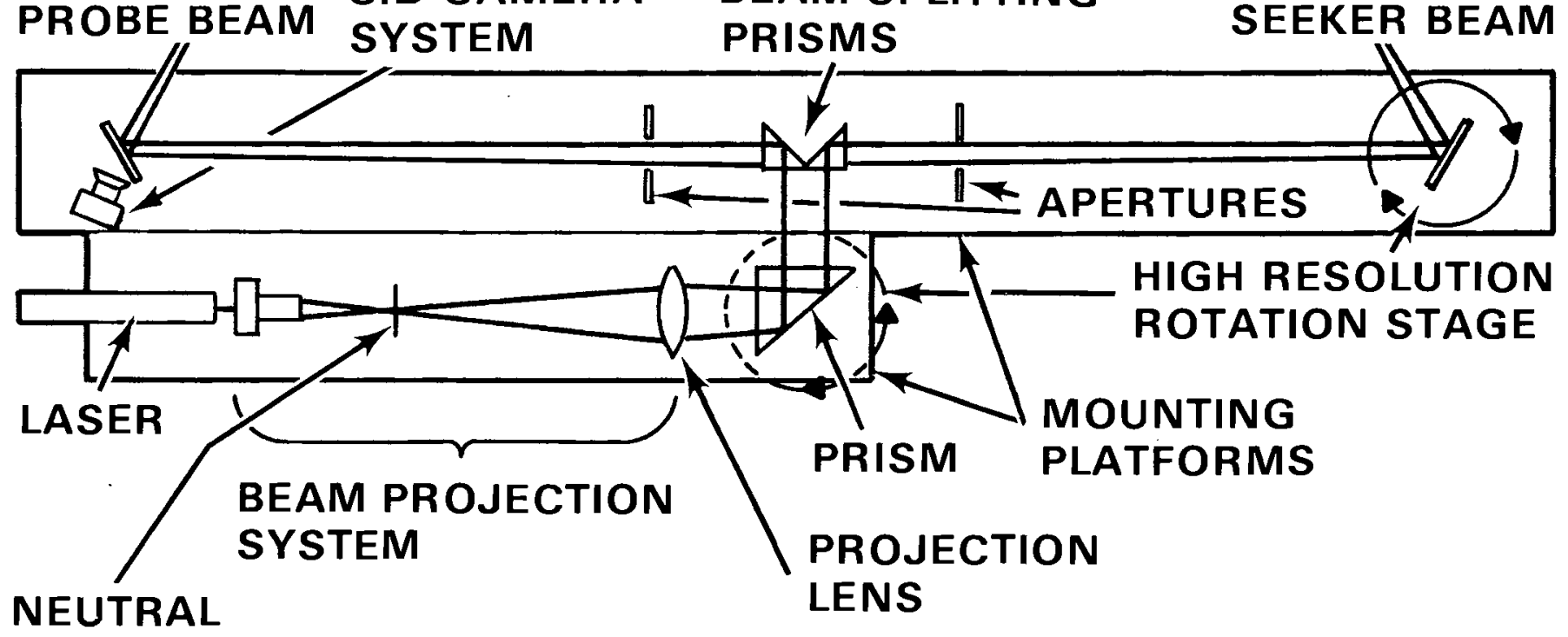

FILTER
TO TEST SURFACE

BEAM SPLITTING PRISMS ROTATION STAGE

FIGliRE 8. Schematic of Field Version of OTP System 


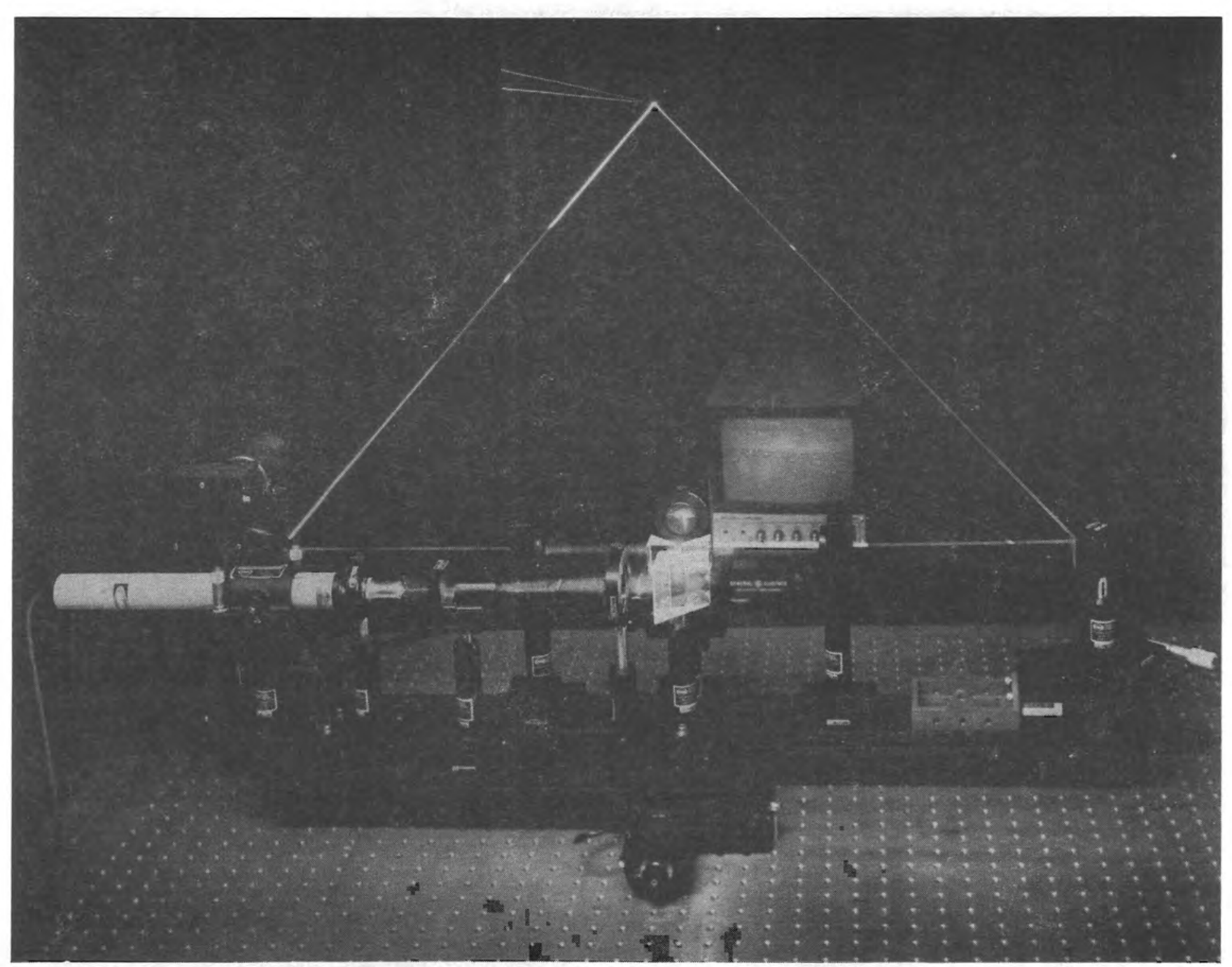

FIGURE 9. Photograph of OTP Field System 
expect that optimization of the mechanical, optical, and coincidence discrimination components will allow achievement of the $0.1 \mathrm{~mm}$ resolution goal.

\section{OPTICAL PHASE RANGING PROFILOMETRY (OPRP)}

THEORY

Optical phase ranging profilometry is based upon the technique of position location by phase difference detection. A schematic of the concept appears in Figure 10. An intensity modulated laser beam is split into two parts, one traversing a reference path within the instrument and the other acting as a probe beam for illumination of the surface under investigation. The reference beam is made to fall incident onto a detector the output of which is fed to a low gain, narrow band pass amplifier. Surface scattered light at the probe beam illumination point is re-imaged via an optical system onto an identical detector whose output is boosted by a narrow band pass amplifier. If the detector/amplifier systems are electrically matched, a phase difference between the reference and probe signals will exist which is solely determined by the optical path difference encountered by the two beams.

The magnitude of the phase difference is determined by three factors; these are: 1) the modulation frequency, 2) the optical path difference (OPD), 3) phase shifts introduced by unmatched detector/amplifier subsystems. Each of these factors will now be considered in detail. An intensity modulated beam may be considered as an amplitude modulated envelope with traveling nulls (points of minimum intensity) spaced $\lambda$ apart. For modulation at frequency $f, \lambda$ is given by

$$
\lambda=\frac{c}{f}
$$

where $c$ is the speed of 1 ight $\left(c=2.99 \times 10^{10} \mathrm{~cm} / \mathrm{sec}\right)$. The magnitude of the phase shift between two modulated beams experiencing a path length difference $\Delta \ell$ is 


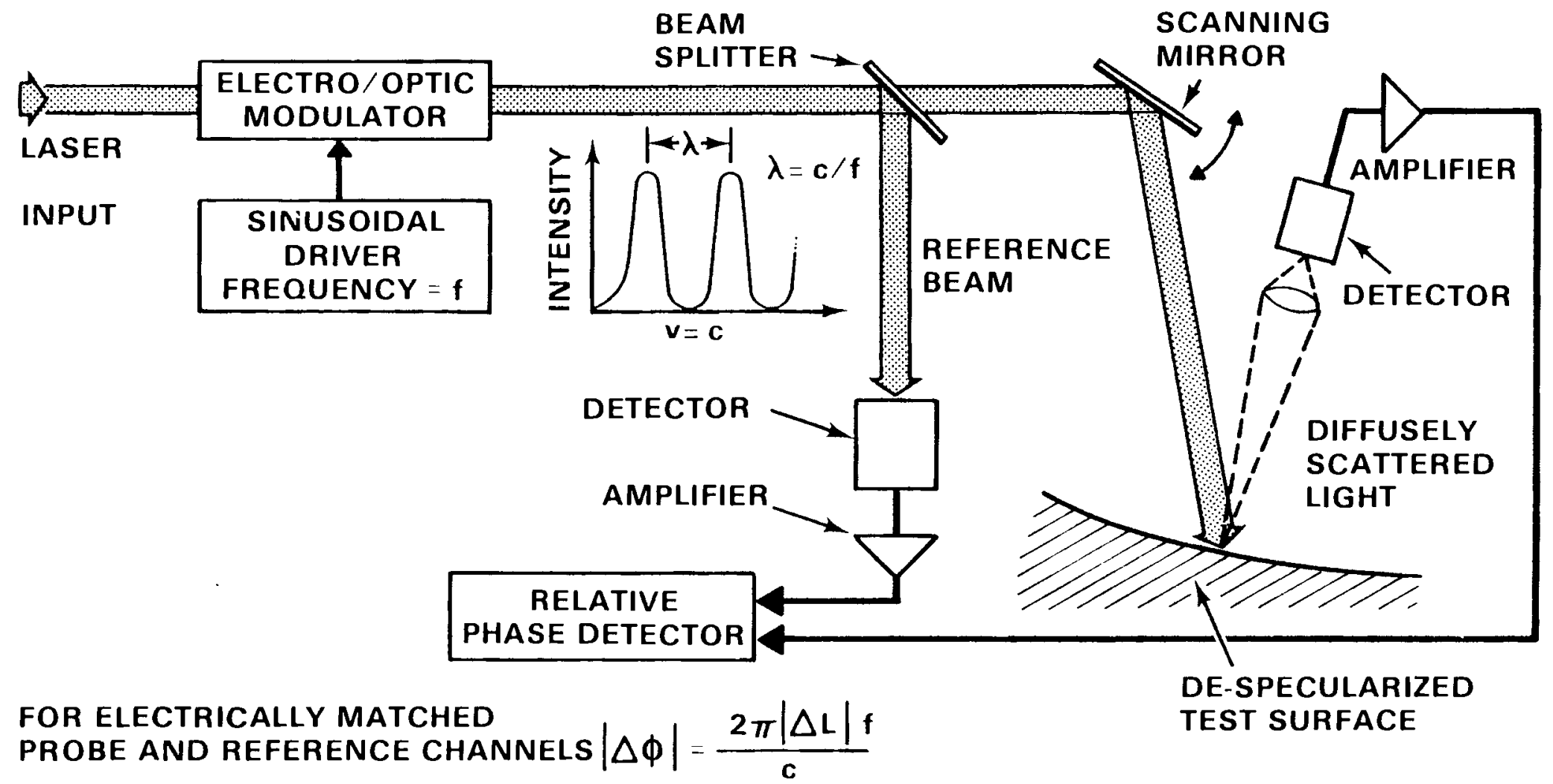

WHERE $\triangle$ IL IS THE OPTICAL PATH LENGTH DIFFERENCE BETWEEN THE TWO LEGS 


$$
\Delta \phi=\frac{2 \pi|\Delta l|}{\lambda}=\frac{2 \pi|\Delta l| f}{c}
$$

or $(360|\Delta \ell| f) / c$ degrees. Note that for a given $\Delta l$ the apparent phase difference is a function of the modulation frequency $f$.

The phase ranging technique provides a method for determining absolute optical path differences between probe and sample beams. In general however, such absolute information is not needed or desired and relative phase shifts are sufficient to characterize the test surface for purposes of quality analysis. Since the optical radiation in the reference leg is of relatively high intensity, lens imaging of this radiation onto the detector surface is not necessary. This results in all components comprising the beam profile arriving at the detector in phase. Such is not the case for the re-imaged probe signal. This situation is depicted in Figure 11. Note that for light traversing different portions of the imaging optic the optical path length is different. This results in signals reaching the detector which are spread in phase throughout some range of values. Depending upon the required system resolution this may or may not be a problem. If such phase scatter is intolerable corrective measures such as severe aperture restriction at the imaging optic or path equalization with corrector plates are possibilities.

Phase shifts between the reference and probe signals which are results of differing electrical transfer functions in the detector/amplifier electronics are generally not a problem unless they are time dependent. Some time dependent phase shift may be introduced by component temperature fluctuations. This can be alleviated to some degree by allowing sufficient warmup time and if possible by controlling the ambient temperature of the environment. Since most techniques of phase detection exhibit some sensitivity to signal amplitude fluctuation, apparent phase noise may be the result of random noise in the detectors and/or amplifiers.

\section{IMPLEMENTATION}

The OPRP system may be broken down into four subsystems; these are: 1) the modulation subsystem comprised of the master oscillator, power amplifier, modulator and load, 2) the optical subsystem composed of the scanning 


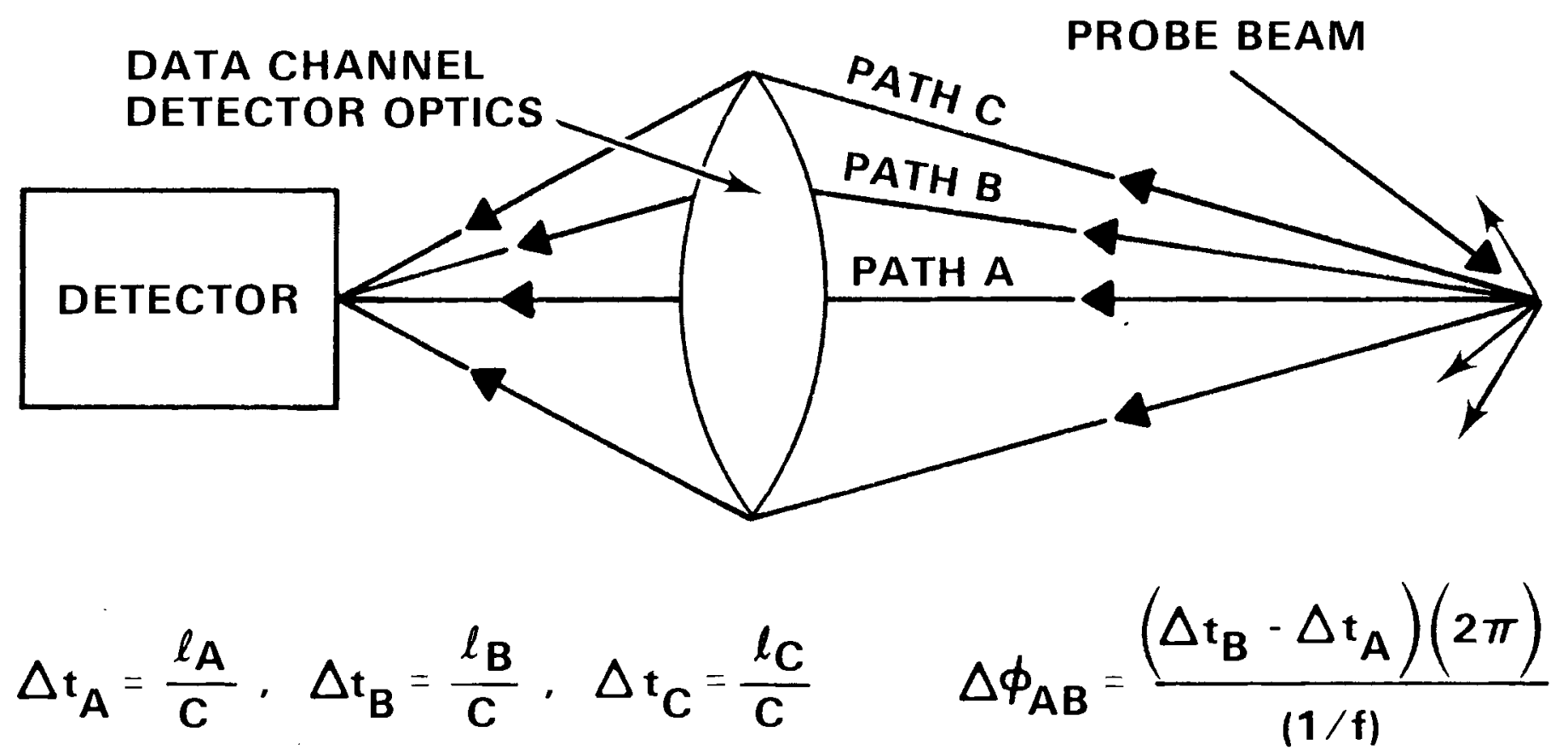

FIGURE 11. Time Dispersion in Re-Imaged Probe Beam Components 
and imaging optics, 3) the detector/amplifier subsystems, and finally 4) the phase detection subsystem. These four subsystems will now be discussed in detai1.

The key component in the modulation subsystem is the modulator itself. It was shown previously that the phase difference, $\Delta \phi$, created by a path difference $\Delta l$ is a function of the modulation frequency, $f$. A higher modulation frequency lessens the resolution requirements on the phase detection electronics for a given $\Delta l$. Currently available electro-optic modulators can operate at frequencies exceeding $1 \mathrm{GHz}$. These modulators are crystal devices comprised of an array of optically active elements whose birefringence characteristics are determined by the applied voltage. Used in conjunction with a polarizer and analyzer these devices are capable of amplitude modulating a raw laser beam. The devices are typically non-linear (i.e., I out $\propto \sin ^{2}(\alpha+\beta V)$, where $V$ is the applied voltage) and even if operated in the pseudo linear region will introduce some distortion in the output intensity waveform. This situation causes no difficulty if the reference and probe signals are derived from the modulated beam. For this reason it is not advisable to base the phase comparison on the modulator drive and probe detector signals. Most high frequency modulators are designed as simple transmission lines, that is, electrically they appear as a $50 \Omega$ unterminated coaxial cable. This configuration greatly simplifies the modulator drive technique.

The modulator driver system is comprised of a master oscillator, power amplifier, and termination. The master oscillator should be crystal controlled and possess good frequency stability. Required power output is determined by the input level requirements of the power amplifier.

The modulation depth of the light exiting the output of the modulator is determined by the peak to peak value of the applied drive voltage. Since typical half wave voltages (i.e., that voltage required to drive a modulator from maximum to minimum transmission) for high frequency electro-optical modulators are on the order of hundreds of volts, the required drive powers can be on the order of hundreds of watts. Radio frequency amplifiers at these power levels can be very exotic and expensive so that due consideration should be given to drive requirements before a modulator is chosen. 
Since the modulator appears electrically as a $50 \Omega$ coaxial line it is necessary to terminate the output side with a $50 \Omega$ load. This termination should be selected on the basis of power handling capability and low voltage standing wave ratio (VSWR).

The optical subsystem which is composed of the scanning and imaging optics and drive stages should satisfy the same basic criteria established for the OTP system. The resolution requirement on the scanning mirror rotary stage is determined by the desired data resolution on the test surface. Once aga in either the rotary stage drive shaft position or the stage position itself should be encoded for data acquisition. The imaging optics used to image the scattered probe illumination onto the probe detector should be of high quality and should introduce minimal image aberration. Once again if possible the illumination point should lie on the optical axis to avoid excessive off axis image aberration. Depending on the tolerable phase spread in the probe signal it may be necessary to limit the clear aperture of the optical system or insert a correction plate to bring off axis components into phase.

Several options exist for the choice of components in the detector/amplifier subsystems. For high speed detectors one may choose from PIN diodes (PIND), avalanche photodiodes (APD) or high speed photomultiplier tubes. While the cost of PIND's and APD's is relatively low, their exceedingly small active areas make them particularly sensitive to image jitter. The photomultiplier on the other hand, while in general having a slower response time, does have a much larger active surface area and higher intrinsic gain. Since the relative phase between the surface incident light and the detector output may vary with position on the tube face care must be taken to aperture the detector so that only a small portion of the active surface is utilized. The signal amplifiers connected to the detector output should be input impedance matched to the detector output impedance. Impedance mismatches will result in ringing and signal distortion. The required gain of the amplifiers is dependent upon detector signal output level and the amplitude requirements of the phase detection system. The bandwidth of these amplifiers should be 
narrow to eliminate wide band detector introduced noise and to suppress harmonics possibly introduced by the modulation system.

Crucial to successful implementation of the OPRP system is the performance of the phase detection system. Resolution capabilities of phase detection schemes are generally better as operating frequency is lowered. For this reason it is sometimes desirable to mix down the output signal of the detector amplifiers. Note that this technique requires an additional high frequency oscillator for difference extraction. If possible this signal should be derived from the master oscillator so as to avoid relative drift between two unsynchronized sources. Choice of the phase detection scheme will be determined by the operating frequency and the resolution requirements. Since the resolution capability of most phase detection systems may be enhanced by signal averaging techniques, it may be necessary to insure that the proposed system have computer interface capability.

\section{EXPER IMENTAL TECHNIQUE}

The OPRP feasibility investigations were performed at two frequencies, 50 and $500 \mathrm{MHz}$. For the first set of experiments $(50 \mathrm{MHz})$, a commercial modulation system was used with upper frequency capability of $50 \mathrm{MHz}$. For the latter experiments ( $500 \mathrm{MHz}$ ), a comercial modulator with $1 \mathrm{GHz}$ bandwidth was driven with an in-house designed oscillator/power amplifier subsystem.

The $50 \mathrm{MHz}$ experiments were performed using a Coherent Associates Model 3050 modulation system. The bandwidth of this unit was dc $-50 \mathrm{MHz}$. The video input was supplied by a variable radio frequency oscillator. This modulation system was equipped with automatic bias control ( $A B C$ ) which limited operating point shifts due to crystal temperature fluctuation and electrical drift. The design operating point of the $A B C$ system was at the minimum of the $\sin ^{2}$ crystal characteristic. While this is desirable when using the modulator for digital applications (one directional voltage swings, 0 to 5 volts) it causes bipolar inputs to experience frequency doubling. Consequently to produce $50 \mathrm{MHz}$ modulation it is only necessary to drive the video 
input at $25 \mathrm{MHz}$. This was found to be an asset however, because stray $50 \mathrm{MHz}$ radiation which could be picked up by the tuned detector amplifiers could essentially be eliminated from the work environment. The modulation system was adjusted to produce an extinction ratio of between 30 and 150 for the $5145 \AA$ argon ion laser line. Beam intensity was kept at the minimum level which allowed the laser power supply regulation system to function properly, general1y around $200 \mathrm{~mW}$. Since the video drive was a sinusoid at frequency $f$, the modulated beam output was nearly sinusoidal at frequency $2 f$.

Photomultiplier tubes (RCA 6199) were used for light detection in both the reference and probe legs. High frequency current buffer amplifiers were used to couple the photomultiplier output to the detector amplifier. While these buffers were not really necessary for close proximity coupling they were deemed necessary for driving long, possibly unmatched coaxial lines feeding other apparatus. The detector amplifiers were tuned solid state units with a full bandwidth of $10 \mathrm{MHz}$ centered around the $50 \mathrm{MHz}$ operating point and a gain of $20 \mathrm{db}$.

Phase detection was performed with a commercial volt/phasemeter (HewlettPackard Model 8405A Vector Voltmeter) which determined the relative phase between the reference and probe signals. A brief description of the principles of operation of this device is in order.

The volt/phasemeter is comprised of a two channel radio frequency (RF) to intermediate frequency (IF) converter, an AC voltmeter, and a phasemeter. The converter changes two RF signals $\left(S_{1}\right.$ and $\left.S_{2}\right)$ which have the same fundamental frequency to two IF signals with $20 \mathrm{KHz}$ fundamental frequency. The IF signals retain the same waveforms, amplitudes, and phase relationship as the RF signals. The $20 \mathrm{kHz}$ fundamental sinusoidal components of the "mixed-down" $\mathrm{S}_{1}$ and $\mathrm{S}_{2}$ signals are extracted from the IF signals by narrow bandpass filters. Before application to the phasemeter the $20 \mathrm{kHz}$ sinusoids are amplified and clipped to remove amplitude variations in either signal, thereby enhancing the relative phase characteristic. In the phasemeter the clipped sine waves become triggers spaced in time. The time separation is proportional to the phase difference between the two signals. The time resolved triggers are used to generate a square wave with symmetry proportional to the time separation and therefore to 


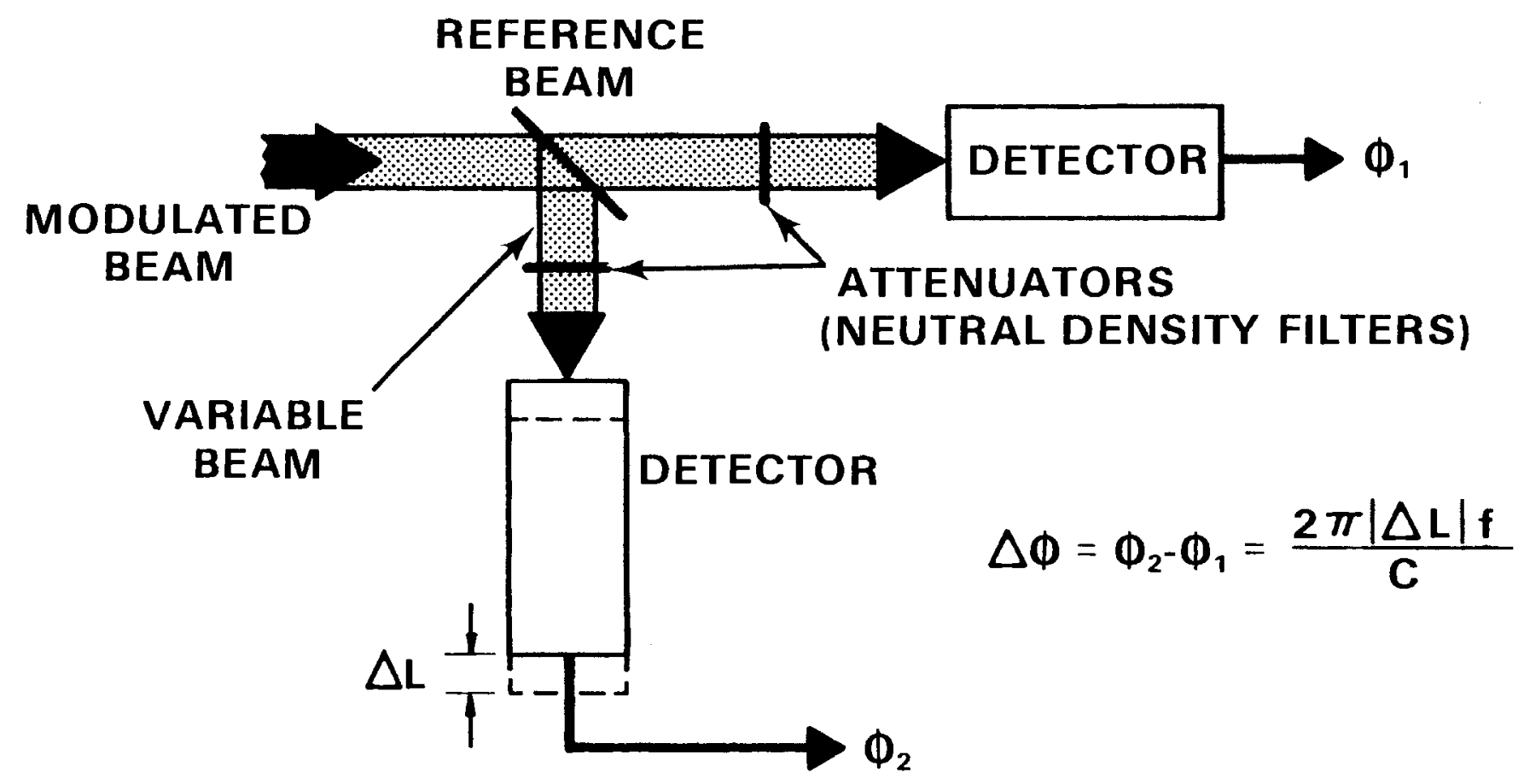

FIGURE 12. Coriponent Configuration for Resolution Evaluation of $50 \mathrm{Mllz}$ OPRP System 
the relative phase. This square wave controls the current that operates the phase meter. The average meter current is governed by the square wave symmetry thus the meter indication is proportional to the phase difference between the original two RF input signals $S_{1}$ and $S_{2}$ (reference and probe).

The effective wavelength of the $50 \mathrm{MHz}$ beam is given by $\lambda=c / f=$ $\left(2.99 \times 10^{10} \mathrm{~cm} / \mathrm{sec}\right) /\left(50 \times 10^{6} \mathrm{sec}^{-1}\right)=5.98 \mathrm{~m}=598 \mathrm{~cm}$. The phase shift per unit path differential is therefore $(360$ degrees $/ 598 \mathrm{~cm})=0.602$ degrees $/ \mathrm{cm}$.

For system evaluation the $50 \mathrm{MHz}$ OPRP components were configured in the manner shown in Figure 12. Neither reference or probe beams were focused. Experimental phase variations with detector displacement were found to be consistent with calculated values. The probe and seeker signals were observed to exhibit appreciable relative phase jitter $( \pm 0.2$ degrees) and long term drift. These adverse characteristics were deemed the result of amplitude fluctuation of the probe and reference signals (due to detector and amplifier noise and temperature dependent transfer characteristic variations in the amplifier) and could therefore be remedied by simple signal stabilization and processing techniques.

To decrease the phase resolution requirements, it was desirable to increase the OPRP operating frequency to as high a value as possible. The choice of this operating frequency was strongly influenced by RF component availability and expense and was chosen as $500 \mathrm{MHz}$ where components are available for commercial radio operation. Note that for $500 \mathrm{MHz}$ the relative phase shift per unit path differential is increased an order of magnitude to 6.02 degrees/cm. A schematic of the $500 \mathrm{MHz}$ moculation system appears in Figure 13. A photograph of the apparatus appears in Figure 14.

The modulator drive system consisted of a $0.25 \mathrm{~W}$ output $500 \mathrm{MHz}$ crystal oscillator, a $30 \mathrm{~W}$ intermediate power amplifier, and a $100 \mathrm{~W}$ power amplifier. The output was terminated beyond the modulator with a $125 \mathrm{~W}, 50 \Omega$ air cooled load. The modulator was a dual crystal type with $1 \mathrm{GHz}$ bandwidth optimized for operation at $5145 \AA$. The half wave voltage of this modulator is 650 volts. The high surface conductivity characteristics of the crystals (cesium dideuterium arsenate) excludes the application of high ( $\geq 500$ VDC) bias voltage to control 


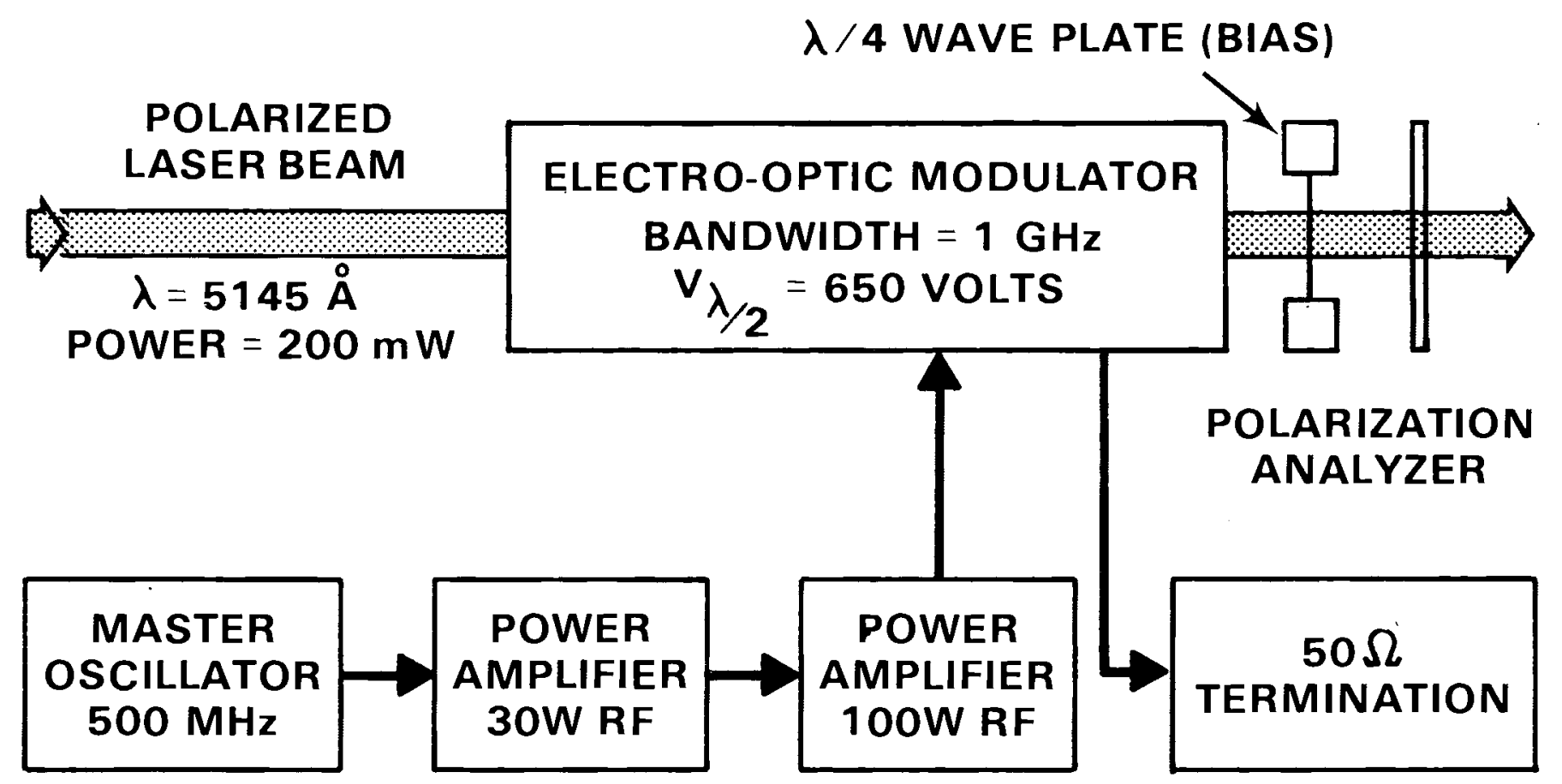

FIGURE 13. $500 \mathrm{MHz}$ Modulation System 


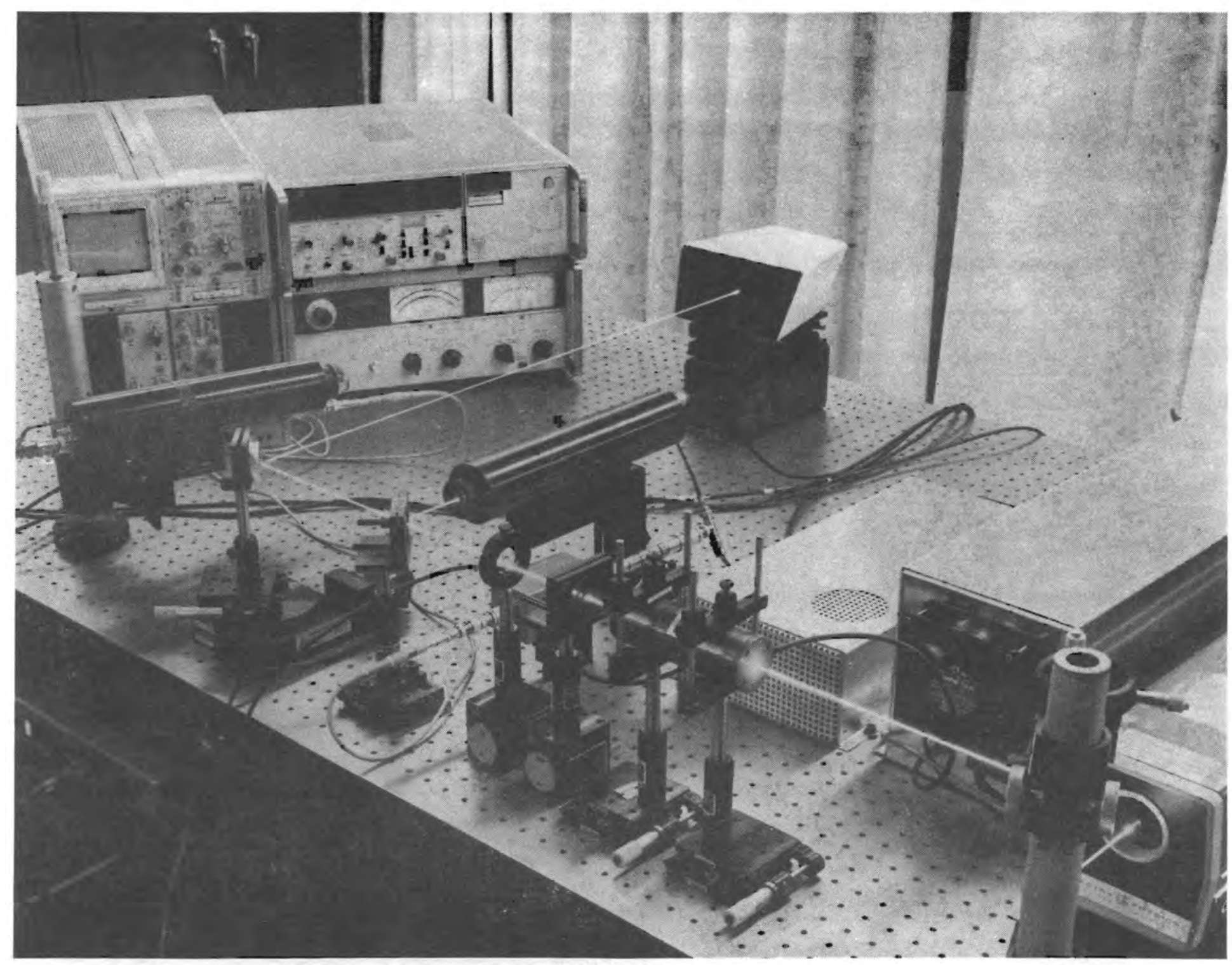

FIGURE 14. Photograph of $500 \mathrm{MHz}$ OPRP System 
modulator operating point. This requires that a rotatable quarter wave plate be inserted between the modulator and analyzer for changes in the quiescent optical transmission.

Optical detection was performed with two high speed photomultiplier tubes (RCA C31024A). These tubes have a characteristic output impedance of $50 \Omega$ and are equipped with $50 \Omega$ shielded coaxial output connectors. Signal amplification and broadband noise suppression was accomplished with a low ga in (10 db) narrowband (500 $\mathrm{MHz} \pm 5 \mathrm{MHz}$ ) preamplifier.

To date the results of the $500 \mathrm{MHz}$ OPRP feasibility experiments have been inconclusive. Uncertainties as to the actual performance of the modulator and detector components have hindered the evaluation of system resolution. Several sources of system deficiency (and areas for system improvement) are thought to be contributors to the current poor performance. First, the modulator being used in the prototype OPRP has not been thoroughly evaluated at high drive powers $(>4 \mathrm{~W})$. While it is desirable to drive the modulator at the highest reasonable power possible in order to maximize modulation depth, the electrical characteristics (i.e., crystal leakage current, electrode breakdown, RF arcing) of the modulator may be inhibiting component performance. Satisfactory resolution of this performance uncertainty requires further investigation. Another area of lesser uncertainty is detector performance. The photomultipliers utilized in this study have been thoroughly evaluated and implemented in high frequency designs (up to $800 \mathrm{MHz}$ ) and the current experiments at $500 \mathrm{MHz}$ should not tax their capability. Clearly the observed output signal at the detector amplifier is a convolution of the transfer characteristics of both modulator and detector so that apparent deficiency in one element may indeed be due to deficiency in the other. Only further investigation will resolve this question. 


\section{SUMMARY}

The results of preliminary feasibility experiments on the OPRP system have been inconclusive. While the concept remains viable from a theoretical standpoint, its implementation is uttimately determined by the performance of the modulation and detection systems. The assessment of the optical and electrical performance of these components will require further investigation.

\section{CONCLUSIONS}

The optical triangulation profilometer (OTP) appears to be a viable option for use in evaluating the figure of solar mirrors. Improvement of resolution capability to $0.1 \mathrm{~mm}$ appears feasible by simply optimizing the optical/electronic designs of the beam projection and coincidence discrimination systems. Development of video image analys is capability for coincidence assessment requires only the development of software for image enhancement algorithms.

Complete feasibility evaluation of the optical phase ranging profilometer (OPRP) requires establishment of the performance capabilities of the modulator and detector components. From a technical standpoint the OPRP is certainly the more elegant and aesthetically pleasing of the two concepts since it employs only a single probe beam and its conceivably small size would enhance field capability. A valid feasibility evaluation of this system requires further investigation. 


\section{REFERENCES}

Griffin, J. W., M. A. Lind, L. D. Philipp, "Evaluation Techniques for Determining the Reflectivity, Specularity, and Figure of Solar Mirrors," Prepared by Pacific Northwest Laboratory for Solar Energy Research Institute (SERI/TR98366-1), May 1980 (Available NTIS).

Griffin, J. W., and M. A. Lind, "The Evaluation of Solar Mirror Figure by Moiré Contouring," Pacific Northwest Laboratory, PNL-3286, June 1980 (Available NTIS). 


\section{ACKNOWLEDGEMENTS}

The authors gratefully acknowledge the assistance and technical support of T. L. Stewart. Mr. Stewart was instrumental in the construction and operation of the prototype optical/electronic systems discussed herein.

Acknowledgement is also due M. S. Nordmeyer for his contribution to the fabrication and testing of components of the auxiliary electronic apparatus. 


\section{DISTRIBUTION}

No. of

Copies

OFFSITE

\section{Technical Information Center}

T. E. Anderson

DSET Laboratories, Inc.

Box 1850

Black Canyon Stage

Phoenix, AZ 85029

D. M. Be11

ACUREX Corp.

$485 \mathrm{Cl}$ yde Ave.

Mounta in View, CA 94042

M. Berry

Boeing Engr. and Const.

PO Box 3707

Seattle, WA 98124

F. Blake

Northrup, Inc., Blake Laboratory

Suite 306

7061 S. University Blvd.

Littleton, CO 80122

T. Blaney

Sunpower Systems Corp.

510 So. 52nd St.

Tempe, AR 85281

F. L. Bouquet

Jet Propulsion Laboratory

4800 Oak Grove Drive

Pasadena, CA 91108

G. Braun

DOE Division of Solar Technology 20 Massachusetts Ave.

Washington, DC 20545

B. Butler

Solar Energy Research Institute 1536 Cole Blvd.

Golden, C0 80401
No. of

Copies

P. Cal1

Solar Energy Research Institute

1536 Cole Blvd.

Golden, CO 80401

W. Carroll

Jet Propulsion Laboratory

4800 Oak Grove Drive

Pasadena, CA 91108

A. A. Churm

DOE Chicago Patent Group

9800 South Cass Avenue

Argonne, IL 60439

S. J. Creamer

CINDAS/Purdue University

2595 Yeager Road

West Lafayette, IN 47906

M. De Vries

Donnelly Mirrors Inc.

$49 \mathrm{~W}$. 3rd St.

Holland, MI 49423

C. R. Easton

McDonnell Douglas Astronautics Co.

5307 Bolsa Ave.

Huntington Beach, CA 92647

P. J. Eicker, 8326

Sandia Laboratories

Livermore, CA 94550

C. R. Frownfelter

$P P G$ Industries, Inc.

One Gateway Center

Pittsburg, PA 15222

R. Gillette

MS 9A-46

Boeing Engr. and Const.

PO Box 3707

Seattle, WA 98124 
B. Gupta

Solar Energy Research Institute 1536 Cole Blvd. Golden, CO 80401

M. U. Gutstein

DOE Division of Solar Technology 20 Massachusetts Avenue

Washington, DC 20545

P. L. Hofmann

Battelle

505 King Ave.

Columbus, $\mathrm{OH} \quad 43201$

C. G. Howard

Booz, Allen \& Hamilton, Inc. 8801 E. Pleasant Valley Road

Cleveland, $\mathrm{OH} 44131$

E. Lam

Bechtel National Inc.

MS $50 / 16$

P0 Box 3965

San Francisco, CA 94119

C. M. Lampert

Lawrence Berkeley Laboratory

B1dg. 62, Rm. 235

University of California

Berkeley, CA 94720

I. E. Lewis

Ford Aerospace

3939 Fabian Way

Palo Alto, CA 94303

V. L. Lindberg

Ford Glass Technical Center

25500 West Outer Drive

Lincoln Park, MI 48146

K. Masterson

Solar Energy Research Institute

1617 Cole Blvd.

Golden, C0 80401
C. L. Mavis

Sandia Laboratories

Livermore, CA 94550

R. McCluney

Florida Solar Energy Center

300 State Road, 401

Cape Canavera1, FL 32920

Mrs. McHugh

Sanders Associates

95 Canal St., MS MER12-1214

Nashua, NH 03061

L. Melamed

DOE Division of Solar Technology

20 Massachusetts Avenue

Washington, DC 20545

W. Mitchel1

Solaramics Inc.

1301 El Segundo Blvd.

E1 Segundo, CA 90245

L. P. 01dham

Martin Marietta Corp.

MS 8130

PO Box 179

Denver, C0 80201

R. Pettit, 5842

Sandia Laboratories

Box 5800

Albuquerque, NM 87115

J. A. Pietsch

Northrup, Incorporated

302 Nichols Drive

Hutchins, TX 75141

J. E. Rannels

DOE Division of Solar Technology

20 Massachusetts Avenue

Washington, DC 20545 
No. of

Copies

J. C. Richmond

National Bureau of Standards

Washington, DC 20234

I. B. Rickling

Florida Solar Energy Center

300 State Road 401

Cape Canaveral, FL 32920

H. Roberts

Solar Energy Research Institute

1536 Cole Blvd.

Golden, CO 80401

A. F. Shoemaker

Corning Glass Works

Corning, NY 14830

W. Tomlinson

Environmenta] Library

758 Eddy St.

Univ. of Montana

Missoula, MT 59812

P. Tremblay

Foster-Miller Associates

135 Second Ave.

Wal tham, MA 02154

J. Vitko

Sandia Laboratories

Livermore, CA 94550

R. R. Wa1ters

E. Systems

Energy Technology Center

PO Box 6118

Dallas, TX 75222

J. D. Walton, Jr., Engineering Experiment Station Georgia Institute of Technology

Atlanta, GA 30332
No. of

Copies

L. Weinstein

McDonnel1 Douglas

Astronautics

5301 Bolsa Ave.

Huntington Beach, CA 92647

Dr. Liang-Chi Wen

Jet Propulsion Laboratory

MS506-328

4800 Oak Grove Drive

Pasadena, CA 91103

ONSITE

2 DOE Richland Operations Office

H. E. Ransom

R. Stewart

125 Pacific Northwest Laboratory

K. Drumbeller

J. W. Griffin

W. Laity

M. A. Lind

R. E. Mahan

A. M. Sutey

Publishing Coordination (2)

Technical Information (5) 
